\title{
Políticas Fiscais para Estabilização da Dívida Pública: uma abordagem de equilíbrio geral aplicada ao Brasil
}

\author{
Octavio Augusto Fontes Tourinho ${ }^{1}$ \\ Angélica Freire de Oliveira Brum²
}

\begin{abstract}
Resumo
Usamos um modelo de equilíbrio geral aplicado dinâmico e determinístico com um agente representativo para avaliar alternativas de política fiscal para o Brasil. As alterações do mix fiscal que mais aumentam o produto per capita de longo prazo (em cerca de $2 \%$ ) são: a redução do consumo do governo acompanhada pela redução da alíquota do imposto de renda sobre o capital e o aumento do investimento do governo financiado pela redução das transferências. A primeira delas também é a que produz o maior aumento do bem-estar. As estratégias de consolidação da dívida pública consideradas usaram apenas um instrumento fiscal e visaram reduzir a dívida pública em $10 \%$ em dez anos e sua estabilização subsequente. Sob o ponto de vista do nível de consumo e do nível do estoque de capital no longo prazo, e do fluxo descontado de bem-estar, o melhor instrumento foi na alíquota do imposto de renda sobre o capital. Sob a ótica do produto no longo prazo, o melhor instrumento foi o investimento do governo, seguido pela alíquota do imposto sobre a renda do capital.
\end{abstract}

\section{Palavras-Chave}

Política fiscal. Dívida pública. Equilíbrio geral dinâmico. Modelos de crescimento.

- Este trabalho é derivado da dissertação de mestrado "Políticas fiscais para estabilização da dívida pública: uma abordagem de equilíbrio geral aplicada à Grécia e ao Brasil", apresentada à Universidade do Estado do Rio de Janeiro, Rio de Janeiro (RJ), Brasil, em 2017. Os autores agradecem os extensos comentários, sugestões e correções de dois pareceristas desta revista que contribuíram muito significativamente para o aprimoramento do artigo. Octavio Tourinho agradece o apoio financeiro do Programa de Incentivo à Produção Científica, Técnica e Artística (PROCIÊNCIA) da Universidade do Estado do Rio de Janeiro (UERJ), financiado com recursos da Fundação de Amparo à Pesquisa do Estado do Rio de Janeiro (FAPERJ) e da bolsa de produtividade do Conselho Nacional de Desenvolvimento Científico e Tecnológico (CNPq). Angélica Brum agradece a bolsa de mestrado da Coordenação de Aperfeiçoamento de Pessoal de Nível Superior (CAPES).

1 Professor - Universidade do Estado do Rio de Janeiro - Endereço: Rua São Francisco Xavier, 524 Bloco C - $9^{\circ}$ andar - Maracanã, RJ - Brasil - CEP: 20550-900 - E-mail: otourinho@uerj.br. ORCiD: orcid.org/0000-0001-8199-3814.

2 Mestre em Economia - Universidade do Estado do Rio de Janeiro - Endereço: Rua São Francisco Xavier, 524 - Bloco C - 9 andar - Maracanã - Rio de Janeiro/ RJ - Brasil - CEP: 20550-900. E-mail: angelica.brum@fgv.edu.br. - ORCiD: orcid.org/0000-0002-9464-5103.

Recebido: 06/12/2017. Aceite: 13/09/2019

Editor Responsável: Dante Mendes Aldrighi

Esta obra está licenciada com uma Licença Creative Commons Atribuição-Não Comercial 4.0 Internacional. 


\begin{abstract}
We used a deterministic dynamic applied general equilibrium model with a representative agent to evaluate fiscal policy alternatives for Brazil. The changes in the fiscal mix that mostly increase the long-run per-capita output (by about $2 \%$ ) are: the reduction of government consumption accompanied by the decrease of the capital income tax rate, and the increase of government investment financed by the reduction of transfers. The former is also the one the produces the largest increase in welfare. The public debt consolidation strategies considered used only one fiscal instrument and aimed to reduce public debt by $10 \%$ in 10 years and its subsequent stabilization. From the point of view of the level of consumption and of the level of capital stock in the long run, and of the discounted flow of welfare, the best instrument was the tax rate on capital income. From the point of view of output in the long-run, the best instrument was government investment, followed by the tax rate on capital income.
\end{abstract}

\title{
Keywords
}

Fiscal policy. Public debt. Dynamic general equilibrium. Growth models.

\section{JEL Classification}

E62. H63. D58. O52.

\section{Introdução}

Os governos dos Estados Unidos e de diversos países da União Europeia, além de vários outros ao redor do mundo, adotaram medidas expansionistas em resposta à recessão mundial de 2007-2010, provocada pela crise financeira originada nos mercados americanos de títulos hipotecários subprime. As medidas de política monetária, conhecidas como Quantitative Easing (QE), visaram principalmente a compra de títulos pelos respectivos bancos centrais para prover liquidez ao sistema financeiro. As medidas de política fiscal foram mais diversificadas e incluíram: i) aumento dos gastos e investimentos públicos; ii) redução da carga tributária; iii) renúncia fiscal; e iv) criação e aumento de subsídios, de acordo com as recomendações gerais da política econômica keynesiana contracíclica. Na maior parte dos países em que foram adotadas, elas levaram à elevação do deficit público primário, financiada em grande parte por acréscimos na emissão de títulos públicos.

Em alguns casos, como Espanha, Portugal, Irlanda e Grécia, essa estratégia foi adotada em um contexto onde a dívida pública já era grande e tinha custo elevado, e isto a colocou em uma trajetória explosiva. O principal 
motivo é a retroalimentação do processo de endividamento que ocorre quando o serviço da dívida é capitalizado, produzindo aumentos sucessivos e crescentes de endividamento que persistem mesmo depois que o deficit primário, o qual deu origem ao processo, é eliminado. Entretanto, existe certo consenso de que é importante evitar a elevação excessiva do endividamento público, porque isso pode reduzir a taxa de crescimento do produto interno bruto (PIB), como apontado por Reinhart e Rogoff (2010; 2011) e comprovado por estudos empíricos subsequentes. ${ }^{1}$ A estratégia utilizada por estes países para enfrentar este problema envolveu a ajuda financeira da União Europeia (UE) e do Fundo Monetário Internacional (FMI), a reversão das políticas que geraram o deficit inicial, e também medidas adicionais de austeridade fiscal para recolocar a dívida pública em uma trajetória sustentável. Com exceção da Grécia, estas medidas surtiram efeitos em alguns anos, estabilizando o endividamento e permitindo a recuperação da economia.

No entanto, os custos da consolidação da dívida em termos de redução do crescimento econômico dependem da trajetória da economia, e podem ser muito elevados, se comparados com valor presente de seus benefícios. Existe um trade off intertemporal de difícil avaliação entre a perda de bem-estar de um ajuste mais rápido e profundo, e os seus ganhos de longo prazo. O custo da estabilização também depende de como o ajuste se distribui entre aumentos de receita e de despesa do governo, e dentro destas categorias, de como os instrumentos fiscais são utilizados. Pela ótica da receita, isto envolve a definição de como são alteradas as alíquotas dos diferentes impostos e tributos, e depende de qual tributo é utilizado como instrumento principal do ajuste. Pela ótica da despesa, ele depende de como o ajuste se distribui pelos diferentes tipos de gasto público (mão de obra, custeio ou investimento) e também dos parâmetros que caracterizam a inserção do governo na economia, como a sua eficiência na provisão de bens e serviços públicos; o impacto do aumento do capital público na produtividade do capital privado; e o peso relativo dos bens e serviços providos pelo Estado no bem-estar das famílias.

Uma situação de desequilíbrio fiscal pode também produzir efeitos indiretos que aumentam a velocidade de aumento da dívida pública, pois o deficit e a dívida elevados levam os credores a exigirem taxas de juros

1 Por exemplo, Tourinho e Sangoi (2017) estimaram, em painel com 86 países com dados anuais de 1983 a 2013, que um aumento de 10 pontos percentuais (p.p.) na razão dívida pública/PIB acarretaria uma redução média de 0,3 p.p. na taxa de taxa de crescimento do PIB per capita. 
maiores, na medida em que aumenta a incerteza quanto à capacidade de financiamento intertemporal do governo. Além disso, a redução da confiança dos agentes diminui o investimento privado e a taxa de crescimento econômico, aumentando a relação dívida pública/PIB. O ajuste fiscal e manutenção da credibilidade quanto ao propósito de assegurar o equilíbrio intertemporal das finanças públicas são de crucial importância para permitir que o governo financie um desequilíbrio transitório das contas públicas com endividamento sustentável. A estratégia ótima para fazer isto não é óbvia, pois os diferentes instrumentos têm impactos dinâmicos distintos, e suas trajetórias devem ser consistentes e sinalizar o comprometimento do governo com o ajuste. Se ela conseguir angariar a confiança dos agentes econômicos, pode-se criar um ciclo virtuoso de aumento da atividade econômica, maior arrecadação, redução do deficit, aumento da taxa de crescimento econômico e eventual redução da dívida pública.

O problema fiscal brasileiro é crônico (Giambiagi e Além 2016), se agravou após a crise mundial de 2007 (Almeida, Lisboa e Pessôa 2015) e se manifesta na aceleração do crescimento da dívida pública bruta. Após se manter em torno de 63\% do PIB de 2007 a 2013, ela alcançou 74,5\% do PIB em dezembro de 2017, e poderá chegar a mais de $92 \%$ do PIB em 2022. ${ }^{2}$ O descontrole das finanças públicas, a instabilidade política por ele gerada e as políticas que se tornaram necessárias para lidar com ele são em grande parte responsáveis pela recessão econômica de 2014-2016, que foi a segunda maior do país no pós-guerra. ${ }^{3}$

O nosso problema fiscal se assemelha, em vários aspectos, àquele descrito de modo genérico anteriormente, o que sugere o emprego de um modelo aplicado de equilíbrio geral dinâmico (dynamic general equilibrium DGE) para examiná-lo. Ele incorpora explicitamente as decisões racionais das firmas e consumidores em um contexto no qual todos os mercados estão em equilíbrio, tanto em cada momento do tempo, quanto intertemporalmente. A comparação do efeito das políticas fiscais sobre um cenário econômico de referência permite diferenciar suas implicações e selecionar as que mais aumentam o produto e o bem-estar médio dos consumidores no horizonte de análise.

Vide IFI (2018).

3 As três piores recessões no Brasil no pós-guerra foram (quedas no PIB em parêntese): 1981-83 (-8,5\%) 1989-92 (-7,7\%) e 2014-2016 (-8,2\%), segundo CODACE (2017). 
Utilizamos aqui o modelo desenvolvido por Papageorgiou (2012) para estudar políticas de mix fiscal e de consolidação de dívida para a Grécia. Ele é um modelo de crescimento ótimo do tipo RCK - baseado nas obras de Ramsey (1928), Cass (1965) e Koopmans (1965) - para uma economia caracterizada por uma função de produção neoclássica com retornos marginais decrescentes dos fatores, estendido de modo a considerar o papel do capital público produtivo. Nele, o aumento da produtividade dos fatores é dado exogenamente, e existe um estado estacionário (EE) que corresponde ao equilíbrio de longo prazo. ${ }^{4}$ As famílias escolhem a trajetória de consumo e da oferta de trabalho de modo a: i) maximizar o valor presente da utilidade do fluxo de consumo futuro; ii) haver substituição entre gasto público e consumo privado na função de utilidade; e iii) haver a possibilidade de transferência intertemporal de consumo por meio da compra e venda de títulos públicos. Na modelagem da política fiscal, são considerados três tipos de dispêndio público e três de tributos, e são levados em conta endogenamente os seus impactos diferenciados sobre o orçamento público, o orçamento e comportamento dos agentes, e sobre o seu bem-estar. A restrição orçamentária intertemporal, por sua vez, permite avaliar se uma determinada trajetória da dívida pública é sustentável. Portanto, o modelo permite avaliar a conveniência de usar uma combinação de instrumentos fiscais para o controle do endividamento público, levando em conta seus efeitos sobre consumo, investimento, poupança, oferta e demanda de trabalho, e sobre o equilíbrio orçamentário dos agentes da economia (governo, família, e firmas).

O modelo DGE determinístico é equivalente ao modelo de equilíbrio geral dinâmico estocástico (dynamic stochastic general equilibrium - DSGE) quando se adota a hipótese de previsão perfeita, que representa uma forma extrema da hipótese de expectativas racionais. Barro (1974) discute o problema do financiamento do governo com dívida pública sob estas condições, e mostra que a sua solução tem a propriedade denominada equivalência ricardiana (Buchanan 1976). Há controvérsias na literatura quanto à validade empírica dessa propriedade, e alguns analistas propõem tratamentos alternativos para o estudo do problema da consolidação da dívida. Este é o caso da abordagem pós-keynesiana que é sintetizada em termos

4 A principal implicação empírica da diferença estrutural entre os modelos de crescimento exógeno e endógeno é que, nos primeiros, a taxa de crescimento do produto per capita declina à medida que a economia se aproxima do EE, isto é, apresentam convergência condicional, enquanto este fenômeno não ocorre nos modelos do segundo tipo. A opção pelo modelo de crescimento exógeno deve-se ao fato de testes empíricos tenderem a rejeitar a hipótese de ausência de convergência (ver, por exemplo, Caselli, Esquivel e Lefort 1996). 
conceituais, por exemplo, em Kregel (1985), Davidson (1991), Carvalho (2008) e Arestis (2011; 2012). Ela foi aplicada ao estudo da dívida pública brasileira por Oreiro et al. (2003) e Hermann (2006), e foi contrastada com a abordagem convencional por Lopes e Mollo (2011) e Montes e Alves (2012a; 2012b). A principal implicação dessa literatura para este texto é relativizar a premissa do nosso estudo, que é a necessidade de controlar o endividamento público excessivo.

O restante deste texto se organiza do seguinte modo. A próxima seção faz uma breve resenha da inclusão da política fiscal e endividamento público em modelos de crescimento econômico, ressaltando os estudos realizados para a economia brasileira. A seção 3 descreve o modelo aqui utilizado e sua solução. A seção 4 discute a sua calibração para o Brasil, as implicações do uso de combinações alternativas de instrumentos fiscais e os resultados do emprego de diferentes instrumentos na consolidação da dívida pública. A última seção sintetiza as principais conclusões e indica direções em que ele pode ser estendido.

\section{Política Fiscal em Modelos de Crescimento}

Nesta seção faremos uma breve resenha da literatura que trata da inclusão do governo em modelos de crescimento exógeno - RCK - e endógeno - tipo AK, segundo caracterização de Rebelo (1991). Os trabalhos até o início do século foram resenhados por Zagler e Dürnecker (2003). Entre aqueles baseados no modelo RCK destacam-se Ballard et al. (1985), Aschauer (1989), Cooley e Hansen (1992), Baxter e King (1993), Barro e Sala-i-Martin (1993), Dotsey e Mao (1994), Devarajan, Swaroop e Zou (1996), Turnovsky (1996), Ludvigson (1996) e Baier e Glomm (2001). Barro e Sala-i-Martin (2004) sintetizam a estrutura desses modelos considerando instrumentos fiscais similares aos do modelo que utilizamos aqui: i) impostos ad valorem sobre consumo, renda do trabalho, renda do capital privado e lucro das firmas; e ii) gastos públicos na função utilidade das famílias e na função de produção. Entretanto, eles não discutem a possibilidade de endividamento público.

A introdução do governo nos modelos AK foi inicialmente proposta por Barro (1990), considerando uma função de produção linear com relação 
a um amálgama de capital privado e gasto público. O modelo foi generalizado por Saint-Paul (1992) e Turnovsky (1996), e estendido para o contexto estocástico em Turnovsky (1999) e Glomm e Ravikumar (1994). Turnovsky (1997) e Aschauer (2000) o estenderam de modo a incluir investimento público em infraestrutura. Leeper e Yang (2008) e Uhlig (2010) incluem endividamento público nesse tipo de modelo e exploram as condições para a sua sustentabilidade. Para situar a nossa contribuição na literatura nacional, comentamos a seguir os trabalhos que aplicam esses modelos à análise dos efeitos estruturais da política fiscal brasileira. ${ }^{5}$

Pereira e Ferreira (2010) consideram uma função utilidade aditiva no logaritmo do consumo e do lazer, proposta por Christiano e Eichenbaum (1992), com aversão relativa ao risco unitária. A oferta de trabalho é endógena, o consumo do governo é exógeno, e há quatro tipos de impostos: sobre produto, consumo, capital e salários. O governo mantém o orçamento equilibrado e a dívida pública é constante. A política fiscal é caracterizada pela escolha das alíquotas dos impostos e a distribuição da receita do governo entre investimento público, transferências e pagamento de juros. Eles estudam os efeitos da proposta de reforma tributária de 2008, e confirmam seus efeitos positivos sobre o produto.

Tanto Mussolini e Teles (2012) quanto Teles e Mussolini (2014) utilizam a mesma função utilidade de Pereira e Ferreira (2010), mas consideram apenas um tributo lump-sum. O modelo deles é estocástico, do tipo de Kydland e Prescott (1982), estendido para incluir choques fiscais exógenos como proposto por Lansing (1998). Em vez de construir e avaliar cenários determinísticos para o vetor de primeiro momento das variáveis endógenas, eles procuram reproduzir fatos estilizados relativos à matriz de segundo momento dos componentes do produto. Eles concluem que o modelo em geral representa bem magnitude da reação da economia aos choques que simulam, apesar de subestimar consideravelmente a variação do consumo privado e superestimar a volatilidade do consumo do governo.

Santana, Cavalcanti e Paes (2012) usam um modelo similar ao de Pereira e Ferreira (2010), mas consideram o consumo do governo endógeno, e supõem que o consumidor extrai utilidade de um amálgama do bem público e do bem privado, na linha do que fazem Baier e Glomm (2001). O modelo deles também é de orçamento equilibrado, e a dívida pública é constante. São feitas quatro simulações de aumento do investimento pú-

5 Para efeitos nas flutuações após 1994, ver Rocha (2009). 
blico, considerando diferentes alternativas para financiá-lo. Os resultados sugerem que o financiamento pela redução do gasto corrente é benéfico, o financiamento pela redução dos outros gastos não é factível para o setor público, e o financiamento com aumento da tributação reduz os efeitos positivos da elevação do capital público.

O modelo de Mereb e Zilberman (2013) usa uma função utilidade instantânea do tipo de aversão relativa ao risco constante (constant relative risk aversion - CRRA), e leva em conta o prazo de maturação dos investimentos públicos de acordo com a formulação proposta por Leeper, Walker e Yang (2010). Eles consideram três tipos de impostos ad valorem sobre consumo, renda do trabalho e renda do capital, e introduzem no modelo um mecanismo não linear de correção de erros, fazendo a alíquota de cada imposto se ajustar ao desvio entre a dívida corrente e a dívida no EE. Eles concluem que estas extensões reduzem dramaticamente o impacto expansionista do investimento público relativamente ao do modelo básico.

Tourinho, Mercês e Costa (2013) analisam a estabilização da dívida pública no Brasil usando um modelo DSGE baseado em Galí, López-Salido e Vallés (2007), e mostram que se o governo mantivesse a partir de 2012 um superavit público primário da ordem de 3\% do PIB, a razão dívida/PIB seria estabilizada, a taxa de juros seria reduzida e a taxa de crescimento se manteria estável, em torno de 3\% a.a. Ele é mais geral do que os modelos que supõem a existência de uma família representativa, pois considera a existência de dois tipos delas - ricardiana e rule-of-thumb - e também permite a análise dos efeitos dinâmicos dos choques fiscais estocásticos. Em contrapartida, ele considera um rol limitado de instrumentos fiscais, e não reserva um papel especial ao capital público na função de produção agregada.

O trabalho de Bezerra et al. (2014) usa uma formulação similar à empregada por Santana, Cavalcanti e Paes (2012) e separa o investimento das estatais daquele das administrações públicas, para detalhar a análise dos seus efeitos diferenciados. Ele faz três simulações contrafactuais referentes a variações de parâmetros de política fiscal no EE, e conclui que a estratégia ótima seria privilegiar os investimentos em infraestrutura das administrações públicas, evitando, desse modo, o crowding-out que decorreria dos investimentos nas estatais. 
O modelo empregado neste trabalho tem uma especificação mais geral do que aqueles mencionados anteriormente, pois considera: i) uma função de utilidade do tipo CRRA (portanto, com elasticidade de substituição intertemporal não unitária); ii) a combinação do consumo privado e do governo para compor o consumo total; iii) uma função de produção que inclui capital privado e público; iv) a possibilidade de ocorrência de deficit; e $v$ ) o seu financiamento por dívida pública e seis instrumentos de política fiscal: três alíquotas de impostos e três tipos de dispêndios públicos.

\section{Metodologia}

Nesta seção, discutimos a especificação do modelo empregado e a sua solução, deixando para a próxima a sua calibração e simulação para a economia brasileira.

\subsection{Especificação do Modelo}

Usamos o modelo de Papageorgiou (2012), que, em síntese, representa uma economia competitiva do tipo Robinson Crusoe, ${ }^{6}$ sem setor externo, ${ }^{7}$ estendida para incluir o governo. Há apenas um bem de consumo, que serve indistintamente para consumo e investimento, seja das famílias ou do governo. As famílias são idênticas, proprietárias da totalidade dos estoques de fatores de produção (capital e trabalho) e os alugam para as firmas. Com a renda obtida, elas adquirem o bem de consumo das firmas e poupam para investir em capital físico e adquirir títulos do governo. As firmas também são idênticas e utilizam capital, trabalho e infraestrutura pública como insumos da produção. Na medida em que há apenas uma família e uma firma representativa, esta firma é de propriedade integral da família, todo o lucro gerado é integralmente distribuído na forma de

Para a formulação e solução do equilíbrio em uma economia desse tipo, ver Varian (1992, 349-351).

7 O modelo de Papageorgiu (2012) não explicita o papel do setor externo, mas isso não é uma limitação importante para a sua aplicação ao Brasil porque a economia brasileira é muito fechada, como se verifica fazendo uma comparação internacional do seu grau de abertura. Segundo IBRE (2013), a corrente de comércio (valor das importações somado ao das exportações) como proporção do PIB do Brasil aumentou de 17\% em 1991 para 25\% em 2011, tendo atingido um pico de 29\% em 2004. Já o seu valor médio no mesmo período passou de $33 \%$ para $57 \%$ entre os Brics+, de $60 \%$ para $74 \%$ nos países da América Latina, e de $66 \%$ para $91 \%$ na média mundial. O fluxo de poupança externa como proporção do PIB foi em média 3,1\% entre 2008 e 2013, atingiu 4,5\% em 2014, mas reduziu-se progressivamente desde então até atingir aproximadamente 0,7\% em 2017 (FIPE 2018). 
dividendos, não havendo retenção de lucros na firma para investimento. Tanto as famílias quanto as firmas agem de forma competitiva. O governo tributa a renda do trabalho, do capital e o consumo privado, e essa receita, acrescida do endividamento líquido, é utilizada para financiar seu consumo, investimento público e transferências. O consumo do governo fornece utilidade às famílias e as transferências aumentam sua renda. $\mathrm{O}$ investimento público aumenta a infraestrutura pública. Não há incerteza. ${ }^{8}$

Admite-se que há $N_{t}$ famílias idênticas e cada uma maximiza a utilidade em um horizonte infinito, tomando os preços e variáveis de política como dados, restrita a uma equação dinâmica que traduz a evolução de sua riqueza, e às condições iniciais e de transversalidade. Admite-se que a função utilidade é temporalmente separável e aditiva, de tal modo que a utilidade na data $t$ é descontada a uma taxa $\rho^{*}>0$ multiplicando-a por um fator de desconto $\beta^{* t}$, onde $\beta^{*}=1 /\left(1+\rho^{*}\right)$ e $\beta^{*} \in(0,1)$, como indicado na Equação (1):

$$
U=\sum_{t=0}^{\infty} \beta^{* t}\left(\frac{\left[\left(C_{t}^{h}+\vartheta \bar{G}_{t}^{c}\right)^{\gamma}\left(L_{t}^{h}\right)^{1-\gamma}\right]^{1-\sigma}}{1-\sigma}\right)
$$

onde se admite também que o governo utiliza seu dispêndio em bens de consumo para fornecer gratuitamente um fluxo contemporâneo de bens e serviços que proporcionam utilidade diretamente aos consumidores. Portanto, o consumo total por família é um agregado linear do consumo privado $C_{t}^{h}$ e consumo do governo médio por família $\bar{G}_{t}^{c}=G_{t}^{c} / N_{t}$ com taxa de substituição $\vartheta \in[-1,1]$. Supõe-se também que a utilidade instantânea é função de um agregado do tipo Cobb-Douglas, com parâmetro $\gamma \in(0,1)$ do consumo total $\left(C_{t}^{h}+\vartheta \bar{G}_{t}^{c}\right)$ e lazer $L_{t}^{h}$, e que ela é do tipo CRRA com parâmetro de aversão ao risco $\sigma \geq 0$. A elasticidade de substituição intertemporal é igual a $1 / \sigma$.

Cada família é dotada de uma unidade de tempo, distribuída entre trabalho $H_{t}^{h}$ e lazer $\left(L_{t}^{h}+H_{t}^{h}=1\right)$, de maneira ótima no contexto da maximização da utilidade da família, que é sujeita à restrição orçamentária dada pela Equação (2):

8 Apresentamos apenas uma síntese da formulação do modelo, destacando os aspectos mais importantes para compreender o seu funcionamento e calibração e interpretar corretamente as suas simulações e conclusões. Para mais informações, ver Papageorgiou (2012).

9 Portanto, a elasticidade de substituição entre consumo total e lazer na família representativa é unitária. 
$\left(1+\tau_{t}^{c}\right) C_{t}^{h}+I_{t}^{h}+D_{t}^{h}=\left(1-\tau_{t}^{l}\right) w_{t} Z_{t} H_{t}^{h}+\left(1-\tau_{t}^{k}\right)\left(r_{t}^{k} K_{t}^{h}+\Pi_{t}^{h}\right)+r_{t}^{b} B_{t}^{h}+\bar{G}_{t}^{t r}+\tau_{t}^{k} \delta^{p} K_{t}^{h}$

O lado esquerdo da equação (2) representa a alocação da renda em: i) consumo, acrescido do seu tributo ad valorem com uma alíquota $\tau_{t}^{c}$; ii) poupança, para investimento em capital físico $I_{t}^{h}$; e iii) poupança, para aquisição de títulos do governo $D_{t}^{h}$.

O lado direito da mesma equação representa as fontes de renda: i) do trabalho, igual ao produto entre: a oferta de trabalho, um índice $Z_{t}$ que representa o progresso técnico exógeno aumentativo do trabalho ${ }^{10}$, e o salário $w_{t}$ por unidade de mão de obra eficiente $\left(Z_{t} H_{t}^{h}\right)$, sendo este total deduzido do imposto ad valorem com uma alíquota $\tau_{t}^{l}$; ii) do capital físico, igual ao produto entre a taxa de retorno do capital privado $r_{t}^{k}$ o estoque de capital da família $K_{t}^{h}$ no início do período $t$, acrescido da parcela do lucro das firmas distribuída em forma de dividendos $\Pi_{t}^{h}$, sendo este total deduzido do imposto ad valorem com uma alíquota $\tau_{t}^{k}$; iii) dos títulos públicos, igual ao produto entre a taxa de juros líquida paga sobre os títulos públicos $r_{t}^{b}$ e o estoque da dívida pública detido pela família $B_{t}^{h}$ no início do período $\left.t^{11} ; i v\right)$ a transferência média por família do governo $\bar{G}_{t}^{t r}=G_{t}^{t r} / N_{t}$; e $v$ ) o ganho tributário advindo da contabilização da depreciação do capital físico como despesa nas firmas, calculado como o produto entre a taxa de depreciação do capital físico $\delta^{p}$, o estoque de capital da família e a alíquota do imposto sobre a renda do capital $\tau_{t}^{k}$. As equações de transição de estado para o capital privado e dívida pública são:

$$
\begin{aligned}
& K_{t+1}^{h}=\left(1-\delta^{p}\right) K_{t}^{h}+I_{t}^{h} \\
& B_{t+1}^{h}=B_{t}^{h}+D_{t}^{h}
\end{aligned}
$$

onde se supõe que $K_{0}^{h}>0$ e $B_{0}^{h}>0$ são dados exogenamente. No equilíbrio descentralizado, cada família escolhe as trajetórias de $\left\{C_{t}^{h}, L_{t}^{h}, H_{t}^{h}, I_{t}^{h}, K_{t+1}^{h}, B_{t+1}^{h}\right\}_{t=0}^{\infty}$ para maximizar (1) sujeito a (2) - (4), tomando os preços e os parâmetros de política fiscal como dados exógenos. No entanto, como se admite que o governo escolhe as trajetórias destes parâ-

${ }^{10} \mathrm{O}$ progresso tecnológico é neutro no sentido de Harrod e cresce de acordo com a expressão $Z_{t+1}=\gamma_{z} Z_{t}$, onde $\gamma_{z} \geq 1$ e $Z_{0}>0$ é dado.

${ }^{11}$ Note que os tributos sobre o rendimento dos títulos da dívida pública não aparecem na Equação (2), o que significa que a taxa de juros $r_{t}^{b}$ deve ser a líquida de impostos. 
metros de modo ótimo, elas são endógenas, do ponto de vista formal. A agregação para todas as famílias (multiplicando por $N_{t}$ ) produz as variáveis agregadas correspondentes, representadas por $\left\{C_{t}, L_{t}, H_{t}, I_{t}, K_{t+1}, B_{t+1}\right\}_{t=0}^{\infty}$.

Admite-se que há um grande número de firmas idênticas indexadas pelo sobrescrito $f^{12}$ e que cada uma produz o único bem, homogêneo, empregando capital privado, trabalho e capital público, de acordo com a função de produção isoelástica da Equação (3):

$$
Y_{t}^{f}=\left(K_{t}^{f}\right)^{a_{1}}\left(Z_{t} H_{t}^{f}\right)^{a_{2}}\left(\bar{K}_{t}^{g}\right)^{a_{3}}
$$

onde $Y_{t}^{f}$ é o produto, $K_{t}^{f}$ e $\underline{H}_{g}^{f}{ }^{f}$ são respectivamente o capital e o trabalho empregados por ela, e $K_{t}^{g t}=K_{t}^{g} / N_{t}$ é o capital público médio por firma (considerado como dado) no início do período $t$. Os parâmetros $a_{1}, a_{2}$ e $a_{3}$ são, respectivamente, a elasticidade do produto em relação ao capital privado, trabalho e capital público, e supõe-se que há retornos constantes de escala com relação a eles, portanto, $a_{1}+a_{2}+a_{3}=1 \mathrm{e}$ $\Pi_{t}^{f}=\left(1-a_{1}-a_{2}\right) Y_{t}^{f}>0$. As condições para maximização de lucro da firma definem os dois preços da economia: $r_{t}^{k}=a_{1} Y_{t}^{f} / K_{t}^{f}$ e $w_{t}=a_{2} Y_{t}^{f} / Z_{t} H_{t}^{f}$. Como os retornos são constantes, e há $N_{t}$ firmas e $N_{t}$ famílias idênticas, $K_{t}^{f}=K_{t}^{h}, H_{t}^{f}=H_{t}^{h}$ e $Y_{t}=N_{t} Y_{t}^{f}$.

A restrição orçamentária do governo em cada período na Equação (6) garante que os ingressos devem ser iguais aos dispêndios totais, ou seja, que o deficit corrente total deve ser financiado por endividamento público, supondo que não há inflação e imposto inflacionário. ${ }^{13}$

$$
B_{t+1}+\tau_{t}^{c} N_{t} C_{t}^{h}+\tau_{t}^{l} N_{t} w_{t} Z_{t} H_{t}^{h}+\tau_{t}^{k} N_{t}\left[\left(r_{t}^{k}-\delta^{p}\right) K_{t}^{h}+\Pi_{t}^{h}\right]=G_{t}^{c}+G_{t}^{t r}+G_{t}^{i}+\left(1+r_{t}^{b}\right) B_{t}
$$

Onde $G_{t}^{i}$ é o investimento público e as outras variáveis são como anteriormente definidas. A condição de transversalidade (7) em conjunto com (6) garante a convergência do valor presente da dívida pública e o equilíbrio intemporal da do orçamento público.

$$
\lim _{T \rightarrow \infty}\left(\prod_{j=1}^{T}\left(1+r_{j}^{b}\right)^{-1}\right) B_{T+1}=0
$$

12 Por simplicidade, o modelo supõe que o número de firmas é igual ao de famílias.

${ }^{13}$ Supóe-se que o título público tem maturidade igual a um período. 
A equação de transição de estado do capital público com taxa de depreciação $\delta^{g}$ é:

$$
K_{t+1}^{g}=\left(1-\delta^{g}\right) K_{t}^{g}+G_{t}^{i} \text { dado } K_{0}^{g}>0
$$

O sistema de equações marginais correspondente aos problemas de maximização da família e firma representativa sob as restrições indicadas acima representa o equilíbrio walrasiano. ${ }^{14}$ Dele deriva-se um sistema estacionário representando as variáveis em unidades de trabalho eficiente, definidas a partir das variáveis agregadas por $x_{t} \equiv X_{t} /\left(N_{t} Z_{t}\right)$, onde $X_{t}$ é uma variável agregada genérica, $x_{t}$ é a variável correspondente por unidade de trabalho eficiente e $N_{t}$ é o número de famílias. O número de horas trabalhadas por família, definido como $h_{t} \equiv H_{t} / N_{t}$, é uma exceção a esta regra geral. ${ }^{15} \mathrm{Su}$ põe-se também que $N_{t}$ cresce à taxa constante $\gamma_{n}$. Disso resulta o sistema de oito equações dinâmicas - de (9) a (16) - que governa as trajetórias das oito variáveis endógenas $y_{t}, c_{t}, i_{t}, h_{t}, k_{t+1}, k_{t+1}^{g}, r_{t}^{b}, b_{t+1}$.

$$
\begin{aligned}
& \frac{\left(c_{t}+\vartheta g_{t}^{c}\right)}{y_{t}}=a_{2} \frac{\left(1-\tau_{t}^{l}\right)}{\left(1+\tau_{t}^{c}\right)} \frac{\gamma}{(1-\gamma)} \frac{1-h_{t}}{h_{t}} \\
& \frac{\gamma_{[}\left[\left(c_{t+1}+\vartheta g_{t+1}^{c}\right)^{\gamma}\left(1-h_{t}(1-\gamma)\right]^{1-\sigma}\right.}{\left(1+\tau_{t}^{c}\right)\left(c_{t}+\vartheta g_{t}^{c}\right)}=\beta\left[\frac{\left[\left(c_{t+1}+\vartheta g_{t+1}^{c}\right){ }^{\gamma}\left(1-h_{t+1}\right)^{(1-\gamma \gamma}\right]^{1-\sigma}}{\left(1+\tau_{t+1}^{c}\right)\left(c_{t+1}+\vartheta g_{t+1}^{c}\right)}\left(\left(1-\tau_{t+1}^{k}\right)\left(a_{1} \frac{y_{t+1}}{k_{t+1}}-\delta^{p}\right)+1\right)\right] \\
& r_{t+1}^{b}=\left(1-\tau_{t+1}^{k}\right)\left(a_{1} \frac{y_{t+1}}{k_{t+1}}-\delta^{p}\right) \\
& \gamma_{n} \gamma_{z} k_{t+1}=\left(1-\delta^{p}\right) k_{t}+i_{t} \\
& \gamma_{n} \gamma_{z} k_{t+1}^{g}=\left(1-\delta^{g}\right) k_{t}^{g}+g_{t}^{i} \\
& y_{t}=\left(k_{t}\right)^{a 1}\left(h_{t}\right)^{a 2}\left(k_{t}^{g}\right)^{a 3} \\
& y_{t}=c_{t}+i_{t}+g_{t}^{c}+g_{t}^{i}
\end{aligned}
$$

\footnotetext{
${ }^{14}$ Para a derivação das condições marginais, ver Papageorgiou (2012).

${ }^{15}$ Considerando que alocação de horas disponíveis é normalizada como sendo igual à unidade, $h_{t}$, é a proporção de horas trabalhadas.
} 


$$
\begin{gathered}
\gamma_{n} \gamma_{z} b_{t+1}+\tau_{t}^{c} c_{t}+\left[\tau_{t}^{l} a_{2}+\tau_{t}^{k}\left(a_{1}+a_{3}\right)\right] y_{t}-\tau_{t}^{k} \delta^{p} k_{t}= \\
\left(1+r_{t}^{b}\right) b_{t}+g_{t}^{c}+g_{t}^{t r}+g_{t}^{i}
\end{gathered}
$$

onde $\beta=\beta^{*} \gamma_{z}^{\gamma(1-\sigma)}, w_{t}=a_{2} y_{t} / h_{t}$ e $r_{t}^{k}=a_{1} y_{t} / k_{t}$. Há seis instrumentos de política fiscal: as três alíquotas dos impostos ad valorem sobre consumo, sobre renda do trabalho e do capital $\left(\tau_{t}^{c}, \tau_{t}^{l}\right.$ e $\left.\tau_{t}^{k}\right)$; e os três níveis de dispêndios públicos, relativos ao consumo do governo, transferências, e investimento público $\left(g_{t}^{c}, g_{t}^{t r}\right.$ e $\left.g_{t}^{i}\right)$.

Os efeitos diretos das alterações dos instrumentos fiscais podem ser inferidos a partir da sua presença nas diversas equações: $\tau_{t}^{c}$ em (9), (10) e (16); $\tau_{t}^{l}$ em (9) e (16); $\tau_{t}^{k}$ em (10), (11) e (16); $g_{t}^{c}$ em (9), (10), (15) e (16); $g_{t}^{t r}$ em (16); $g_{t}^{i}$ em (13), (15) e (16). Os efeitos indiretos levam em conta a repercussão dessas alterações nas outras variáveis do modelo. No entanto, verifica-se que os efeitos cruciais são sobre a otimização estática da Equação (9), a equação de Euler (10) e a restrição orçamentária (16). Geralmente se considera ser muito difícil, senão impossível, descrever sinteticamente os mecanismos de transmissão de políticas em modelos do tipo do acima especificado devido às interações entre as equações.

O sistema composto pelas Equações (9) a (16) é determinado, pois tem oito equações e oito variáveis endógenas para cada $t$, desde que os valores iniciais delas sejam dados. Note-se que nele aparece a restrição orçamentária das famílias - Equação (16), correspondente à (2) -, mas não a do governo - Equação (4). Isso decorre de um corolário da lei de Walras, que indica que, no equilíbrio de uma economia de trocas com $N$ consumidores, se $N-1$ satisfizer a restrição orçamentária, a do $N$-ésimo também estará satisfeita. Esse resultado pode ser generalizado para uma economia com produção e trocas, e com governo, que é o nosso caso. Portanto, a restrição orçamentária do governo é redundante, e pode ser derivada da restrição orçamentária das famílias e das firmas. ${ }^{16}$

A solução de longo prazo (EE) é obtida fazendo com que todas as variáveis endógenas $(x)$ satisfaçam a condição $x_{t-1}=x_{t}=x_{t+1}=x$ para todo $t$, resultando no sistema composto pelas Equações (17) a (24), cuja solução é empregada na fase de calibração do modelo.

${ }^{16}$ A introdução da restrição orçamentária do governo no sistema de equações deve ser evitada, pois pode levar a problemas numéricos associados a sistemas superdeterminados, pois, nesse caso, haveria duas equações colineares que precisariam ser atendidas exatamente, de modo simultâneo, com grande precisão. 


$$
\begin{aligned}
& \frac{k}{y}=\frac{\beta a_{1}\left(1-\tau^{k}\right)}{\gamma_{z}+\beta\left[\left(1-\tau^{k}\right) \delta^{p}-1\right]} \\
& \frac{i}{y}=\left[\gamma_{n} \gamma_{z}-\left(1-\delta^{p}\right)\right] \frac{k}{y} \\
& r^{b}=\left(1-\tau^{k}\right)\left(a_{1} \frac{y}{k}-\delta^{p}\right) \\
& \frac{c}{y}=1-\frac{i}{y}-\frac{g^{c}}{y}-\frac{g^{i}}{y} \\
& \frac{y}{y}=a_{2}\left(\frac{\gamma}{1-\gamma}\right)\left(\frac{1-\tau^{l}}{1+\tau^{c}}\right) /\left[\frac{c+\vartheta g^{c}}{y}+a_{2}\left(\frac{\gamma}{1-\gamma}\right)\left(\frac{1-\tau^{l}}{1+\tau^{c}}\right)\right] \\
& \frac{y}{y}=(k)^{a_{1}}(h)^{a_{2}}\left(k^{g}\right)^{a_{3}} \\
& \gamma_{n} \gamma_{z}-\left(1-\delta^{g}\right) \\
& \frac{\left(g^{i} / y\right)}{y}
\end{aligned}
$$

\subsection{Solução do Modelo}

A maior parte dos DGEs é resolvida e analisada em sua versão linearizada em torno do EE, e o exercício de simulação usual envolve perturbações de pequena magnitude em torno desse ponto. Esse tipo de solução é bastante utilizado na literatura, ${ }^{17}$ e foi escolhido por Papageorgiou (2012) para obter a solução numérica do modelo e fazer as suas simulações. Entretanto, o EE do modelo se altera com a mudança dos parâmetros que representam a política fiscal no modelo e, como apontam Leeper e Yang (2008), nesse

${ }_{17}$ Por exemplo: Baxter e King (1993), Leeper e Yang (2008) e Uhlig (2010), entre outros. 
caso, é necessário avaliar a qualidade da aproximação linear e estar atento para a possibilidade de que ela não seja boa se o novo equilíbrio não for suficientemente próximo do EE original. Papageorgiou (2012) calculou uma sucessão de soluções do sistema de equações linearizadas correspondente, onde cada uma delas é um passo em direção ao novo equilíbrio, e corresponde à alteração do ponto a partir do qual a expansão linear deve ser feita. Esse procedimento pode ser impreciso se o novo equilíbrio for distante do original, ou se a magnitude dos passos for grande.

Na nossa solução numérica do modelo, o sistema de equações foi resolvido para produzir as trajetórias de equilíbrio geral com o auxílio de um programa que permite a especificação algébrica do sistema de equações, de modo a possibilitar o emprego de rotinas numéricas especializadas para sistemas não lineares e a obtenção de uma solução exata. ${ }^{18}$ Isso nos permite simular uma economia que se comporte de acordo com aquela especificação, bastando para isto caracterizá-la por meio do conjunto de parâmetros e condições iniciais.

A análise dos efeitos sobre o bem-estar utiliza a métrica de Lucas (1990), baseada no subsídio ao consumo necessário para que a família seja indiferente entre a situação antes e depois da alteração de política fiscal. Sejam $V_{0}$ e $V^{*}$ a utilidade intertemporal descontada no equilíbrio estacionário na situação inicial e após as mudanças de política fiscal, respectivamente, então, a variação proporcional permanente no consumo privado que faz com que as famílias sejam indiferentes entre estas duas situações é representada por $\zeta$, calculado na Equação (25), cujo sinal indica se há aumento $(\zeta>0)$ ou redução $(\zeta<0)$ de bem-estar.

$$
\zeta=\left(V^{*} / V_{0}\right)^{\frac{1}{\gamma(1-\sigma)}}-1
$$

\section{Aplicação ao Brasil}

$\mathrm{Na}$ aplicação do modelo ao Brasil, tomamos como referência o ano de 2015, anterior ao ajuste fiscal de 2016-2018, para avaliar políticas alternativas que poderiam ter sido empregadas para fazê-lo. Para isso, primeiro calibra-

${ }^{18}$ Utilizamos General Algebraic Modeling System (GAMS), descrito em GAMS (2013), com a rotina PATH específica para a solução numérica de sistemas de equações não lineares. 
mos o modelo para a economia brasileira, em seguida calculamos o EE e, finalmente, fazemos simulações de mudança da participação dos diversos instrumentos na política fiscal (mix fiscal) e de consolidação da dívida. $\mathrm{Na}$ literatura encontra-se mais frequentemente o primeiro tipo de estudo, mas o segundo é o mais interessante como exemplo do potencial do uso dessa metodologia para o desenho de políticas fiscais que mais se aproximam da situação enfrentada atualmente pelo País.

\subsection{Calibração}

Para a decomposição do produto de acordo com a Equação (20), nos baseamos nas Tabelas Sinóticas no 5 e n⿳0 $16 \_2$ das Contas Nacionais do Brasil (IBGE 2018) entre 2010 e 2016, em valores correntes. O período escolhido foi um compromisso entre os requisitos de ser longo o suficiente para que a média observada representasse uma situação próxima ao EE e ser curto o suficiente para caracterizar a economia brasileira recente. Como o modelo é de economia fechada, a importação líquida foi acrescentada ao consumo privado. A variação de estoques também foi adicionada a ele, de acordo com o procedimento convencional. A Tabela 1 mostra que os componentes do produto são razoavelmente constantes ao longo deste período, mas que há alguma atipicidade em 2016. Os valores adotados constam da última coluna da Tabela 1, e foram estabelecidos considerando os valores médios da coluna anterior, fazendo alguns ajustes marginais para refletir algumas tendências observadas em 2017 e $2018^{19}$ e para compatibilizar a convenção das Contas Nacionais quanto ao investimento das administrações públicas com o seu conceito no modelo. ${ }^{20}$

Tabela 1 - Brasil: componentes do produto (2010-2016)

\begin{tabular}{cccccccccc}
\hline & 2010 & 2011 & 2012 & 2013 & 2014 & 2015 & 2016 & Média & Adotado \\
\hline$c / y$ & 0,60 & 0,61 & 0,61 & 0,60 & 0,61 & 0,62 & 0,64 & 0,61 & 0,62 \\
$g^{c} / y$ & 0,19 & 0,19 & 0,19 & 0,19 & 0,19 & 0,20 & 0,20 & 0,19 & 0,20 \\
$i / y$ & 0,15 & 0,16 & 0,16 & 0,17 & 0,15 & 0,14 & 0,13 & 0,15 & 0,16 \\
$g^{i} / y$ & 0,05 & 0,05 & 0,05 & 0,04 & 0,04 & 0,03 & 0,03 & 0,04 & 0,02 \\
\hline
\end{tabular}

${ }^{19}$ Esse ajuste é subjetivo e corresponde à percepção desta tendência pelos autores.

20 Na Tabela Sinótica 16_2 de IBGE (2016), o setor público é composto pelo setor institucional governo geral, empresas não financeiras públicas e empresas financeiras públicas, mas o modelo não considera estas duas últimas. A conceituação do investimento público e sua medição no Brasil são discutidas em detalhes em Orair (2016), que estima em 2,9\% a taxa de investimento do setor público em 2015. 
A taxa de crescimento populacional de $0,86 \%$ a.a. foi extraída do World Development Indicators (WDI) para 2015 (World Bank 2018). Portanto, $\gamma_{n}=1,0086$. Seguindo Papageorgiou (2012), adotamos o valor de $2 \%$ a.a. para a taxa de aumento exógeno da produtividade da mão de obra. ${ }^{21}$ Santana et al. (2012) também usam este valor. Portanto, $\gamma_{z}=1,02$. A produtividade inicial foi arbitrada como sendo unitária: $Z_{0}=1{ }^{22}$

Um parâmetro crucial para examinar a resposta da economia a diferentes cenários para a dívida é a elasticidade de substituição intertemporal $(1 / \sigma)$, na medida em que ela caracteriza a disposição das famílias para adiar o consumo presente em favor de um consumo maior no futuro. Para calibrá-la empregamos dados da literatura internacional e nacional. Para os Estados Unidos, Hansen e Singleton (1982; 1983) estimam que $1 / \sigma$ está entre 0,5 e 2,0; enquanto Gruber (2013) fica no limite superior daquela faixa. Já Lucas (1990) e Baier e Glomm (2001) calibram seus modelos usando $1 / \sigma=0,5$. Em um estudo que envolveu muitos países, Lluch, Powel e Williams (1977) estimam um modelo desagregado de dispêndio linear estendido (ELES) e encontram uma correlação negativa entre nível de renda per capita e o parâmetro de Frisch $(\omega)$, que implica $1 / \sigma=0,3{ }^{23}$ Já Yogo (2004) estima $1 / \sigma$ entre 0,2 e 0,5 para os países desenvolvidos, ${ }^{24}$ enquanto Liu e Sercu (2009) estimam $1 / \sigma \approx 0,5$ para países em desenvolvimento. Papageorgiou (2012) adotou $1 / \sigma=0,5$ para a Grécia. Issler e Piqueira (2000), estimando a função de utilidade CRRA para o Brasil, encontram $1 / \sigma=0,62$ com dados trimestrais dessazonalizados, $1 / \sigma=1,7$ com dados trimestrais não dessazonalizados, e um valor extremamente elevado $(1 / \sigma \approx 5)$ com dados anuais. Considerando as evidências acima, adotamos $1 / \sigma=0,5$, portanto, $\sigma=2$. Esse valor pode ser comparado com o adotado em Pereira e Ferreira (2010), Santana, Cavalcanti e Paes (2012)

\footnotetext{
${ }^{21}$ Papageorgiou (2012) calibrou esse parâmetro supondo que a taxa de crescimento da renda per capita dos Estados Unidos reflete o aumento da produtividade do trabalho na economia americana, e que esta taxa pode ser extrapolada para capturar o efeito do progresso tecnológico na economia mundial.

22 No Brasil, Gomes, Pessoa e Veloso (2003) estimam que o aumento da produtividade total dos fatores tenha sido responsável por metade do crescimento do produto por trabalhador no período 1950-2000, que teria sido de cerca de 1\% a.a naquele período. Barbosa Filho, Pessoa e Veloso (2010) encontram que produtividade total dos fatores aumentou apenas $11,3 \%$ entre 1992 e 2007, a uma taxa média de $0,71 \%$ a.a.

${ }^{23} \mathrm{O}$ parâmetro de Frisch $(\omega)$ é o inverso da elasticidade de substituição global. No ELES, ela engloba a elasticidade intertemporal, mas não se refere a ela especificamente, e portanto, $\omega \simeq \sigma$. Em sua amostra, os autores encontram $\omega=36 \cdot y^{-0.36}$, onde $y$ é a renda per capita de 1970 pela paridade do poder de compra (PPP) em dólares correntes. Calculando esta estimativa para o Brasil, considerando que $y$ em 1970 foi cerca de US\$ 800 segundo o Ipeadata, temos $\omega \simeq 3,2$. Infere-se, portanto, que a estimativa deles para o Brasil é $1 / \sigma=0,31$.

${ }^{24}$ GomesePaz(2013), aoreplicaremasestimativasdeYogo(2004),notaramqueasequaçõesdelenãopassamno teste de sobreidentificação de Sargan, e consideram que instrumentos inválidos teriam sido empregados.
} 
e Bezerra et al. (2014), que supõem implicitamente o valor unitário, e com Mereb e Zilberman (2013), que escolhem $1 / \sigma=0,3$, indicando ser o valor usual na literatura.

O parâmetro $\vartheta$, que mede a substituição entre consumo público e privado, foi calibrado com base na participação dos gastos públicos na renda, medido pelas Contas Nacionais. Examinando os grandes grupos de despesa (Brasil 2016), verifica-se que, excluindo as transferências e os investimentos públicos, tratados em outras rubricas, restam duas categorias de despesas: pessoal e encargos $(4,0 \%$ do PIB) e outras despesas correntes $(5,3 \%$ do PIB), perfazendo um total de 9,3\%. Considerando que o crescimento vegetativo desses gastos sugere que, na margem, essa participação deve ser maior do que a observada, adotamos $\vartheta=0,10$. Esse valor é conservador, e consistente com Baxter e King (1993) e Leeper, Walker e Yang (2010). Já Bezerra et al. (2014) se baseiam em Ferreira e Nascimento (2005) e Santana, Cavalcanti e Paes (2012), que adotam $\vartheta=0,5$, valor que parece ser alto demais e inconsistente com a preferência revelada dos agentes econômicos na alocação pregressa de sua renda.

Na substituição entre o lazer e o consumo do amálgama de bens públicos e privados, o parâmetro $\gamma$ da função agregadora do tipo Cobb-Douglas na função de utilidade foi calibrado para ser compatível com o tempo dedicado ao trabalho pelas famílias no EE. A PNAD 2009 indica que, em média, elas dedicavam $23,8 \%$ de seu tempo ao trabalho, o que corresponde a pouco mais de quarenta horas semanais na média. Foi adotado o valor $h=0,24$, também utilizado por Santana, Cavalcanti e Paes (2012) e, utilizando a Equação (21), calculamos $\gamma=0,3432$.

Como estamos assumindo retornos constantes de escala, os parâmetros da função de produção podem ser calculados a partir da razão entre o dispêndio com os fatores e o produto. Para a elasticidade do produto com relação ao capital público, usamos $a_{3}=g^{i} / y=0,02$, da Tabela 1. Segundo Santana, Cavalcanti e Paes (2012), esse é também o valor médio observado no período 1995-2006. Para a elasticidade do produto com relação ao capital privado, admitimos $a_{2}=0,392$, que é aproximadamente consistente com 0,433, calculado por Pereira e Ferreira (2010); 0,3686 de Mereb e Zilberman (2013) e Ferreira e Nascimento (2005); e 0,4266 usado por Santana, Cavalcanti e Paes (2012). A elasticidade do produto com relação ao trabalho foi calibrada usando a premissa de retornos constantes de escala: $a_{1}=1-a_{2}-a_{3}=0,588$. 
A taxa de depreciação do capital físico (total) foi estimada em 3,5\% a.a. por Gomes, Pessôa e Veloso (2003), usando o método do inventário permanente. Santana, Cavalcanti e Paes (2012) consideram a presença de capital público na função de produção, supõem que as taxas de depreciação do capital público e do capital privado são iguais, e usam $\delta^{g}=\delta^{p}=0,0345$ . Ferreira e Nascimento (2005) e Paes e Bugarin (2006) também adotam taxas iguais de depreciação para o capital público e o privado, mas encontram valores significativamente mais elevados: 0,0656 e 0,0554, respectivamente. Já Mussolini e Teles (2012) calibram seu modelo utilizando taxas distintas para os dois tipos de capital, mas usam valores maiores que os acima: $\delta^{g}=0,09$ e $\delta^{p}=0,10$. Bezerra et al. (2014) usam valores similares a estes últimos: $\delta^{g}=\delta^{p}=0,0928$. Considerando a importância desse parâmetro para o comportamento da economia no longo prazo, preferimos empregar uma estimativa empírica consistente com a série de investimento das Contas Nacionais, e adotamos $\delta^{g}=\delta^{p}=0,035$. Usando a Equação (18), calculamos $k / y=2,5288$. Usando a Equação (22), calibramos a razão $k^{g} / y=0,3161$, que é aproximadamente consistente com 0,3577 , valor encontrado por Bezerra et al. (2014).

Adotamos as alíquotas dos impostos calculadas por Santana, Cavalcanti e Paes (2012) $-\tau^{c}=0,1902, \tau^{l}=0,2171$ e $\tau^{k}=0,13-$, porque os critérios de calibração que eles utilizaram se adaptam melhor à especificação de nosso modelo. ${ }^{25}$ Apesar de essas tarifas terem sido calculadas para o ano de 2010, consideramos ser possível utilizá-las porque, como mostram Almeida et al. (2017) e Azevedo e Fasolo (2015a; 2015b), as alíquotas daquele ano são representativas para o período 2010-2014. Entretanto, as alíquotas encontradas por estes últimos, e por Bezerra et al. (2014) para 2010, são significativamente diferentes daquelas que adotamos, provavelmente devido a diferenças nos critérios adotados para compatibilizar a

${ }^{25}$ Os autores consideraram tributos sobre o consumo: Imposto sobre Circulação de Mercadorias e Serviços (ICMS), Contribuição para o Financiamento da Seguridade Social (COFINS), Programa de Integração Social (PIS), Imposto sobre Produtos Industrializados (IPI), Imposto sobre Serviços (ISS), Imposto de Exportação (IE), Contribuição de Intervenção no Domínio Econômico (CIDE), Imposto sobre Operações Financeiras (IOF), outros tributos estaduais, taxas estaduais, taxas municipais, taxas federais, Fundo Especial de Desenvolvimento e Aperfeiçoamento das Atividades de Fiscalização (FUNDAF), outros tributos municipais e demais contribuições econômicas. Sobre a tributação sobre o capital, consideram: Imposto de Renda Pessoa Jurídica (IRPJ), Contribuição Social sobre o Lucro Líquido (CSLL), Imposto sobre a Propriedade de Veículos Automotores (IPVA), Imposto Predial Territorial Urbano (IPTU), Imposto de Transmissão de Bens Imóveis (ITBI), Imposto sobre Transmissão Causa Mortis e Doação de Quaisquer Bens ou Direitos (ITCD) e Imposto sobre a Propriedade Territorial Rural (ITR). Tributação sobre o trabalho: contribuição para a Previdência Social, Imposto de Renda Pessoa Física (IRPF), Fundo de Garantia de Tempo de Serviço (FGTS), Previdência estadual, contribuição seguridade do servidor público, salário-educação, Sistema S, Previdência municipal e Patrimônio do Servidor Público (PASEP). 
desagregação dos dados fiscais utilizados por eles com os conceitos e a abrangência das alíquotas dos impostos consideradas nos modelos deles. ${ }^{26}$ O parâmetro $\beta=0,9241$ foi calculado de modo a satisfazer a Equação (17).

Para a meta de longo prazo de $b / y$, adotamos $66 \%$, que foi o valor observado em dezembro de 2015, e corresponde ao valor em 2016 segundo a convenção adotada quanto à data de aferição dos estoques no modelo - vide item iii) na discussão da Equação (2). A hipótese implícita é que a elevação daquela razão para 74\% em dezembro de 2017 não é sustentável no EE.

A taxa real líquida de juros da dívida pública foi calculada para 2016, o último ano do período 2010-2016 considerado na calibração, visando capturar a sua elevação provocada pela crise fiscal e aceleração do endividamento. Utilizamos metodologia análoga à empregada por Bezerra et al. (2014) para calcular esta taxa para 2010. A relação de Fisher geométrica foi utilizada para excluir a inflação medida pela variação do Índice de Preços ao Consumidor Amplo (IPCA) em 2016 (6,29\% a.a.) da taxa de juros implícita sobre a dívida bruta interna de $13,6 \%$ a.a., calculada pelo Banco Central do Brasil para 2016, ${ }^{27}$ resultando em taxa de juros real bruta de $6,88 \%$ a.a. A tributação sobre essa renda foi calculada em 16,5\%, levando em conta a distribuição da dívida pública federal total por prazo de vencimento em dezembro de 2016 (Brasil 2018) e a tributação do Imposto de Renda diferenciada por prazo de vencimento (ver AMBIMA 2018), resultando em uma taxa de juros líquida de $5,75 \%$ a.a. ${ }^{28}$ Este valor foi arredondado para $r^{b}=0,06$, considerando a natureza prospectiva das simulações.

${ }^{26}$ Bezerra et al. (2014), para 2010, encontram: $\tau^{c}=0,158, \tau^{l}=0,161$ e $\tau^{k}=0,338$. As alíquotas médias para 2010-2013 em Almeida et al. (2017) são: $\tau^{c}=0,232, \tau^{l}=0,294$ e $\tau^{k}=0,201$. Já as alíquotas médias para 2010-2014 em Azevedo e Fasolo (2015b) são: $\tau^{c}=0,263 \tau^{l}=0,249$ e $\tau^{k}=0,148$. Algumas diferenças são esperadas, enquanto outras demandariam mais investigação. Em particular, o valor que adotamos para $\tau^{k}$ é consistente com os valores encontrados nos dois trabalhos mais recentes acima, se levarmos em consideração que, no nosso modelo, aquela alíquota não inclui a tributação da renda de juros da dívida pública. Entretanto, o valor elevado encontrado para $\tau^{k}$ em Bezerra et al. (2014), está em desacordo com todos os outros estudos, e é possivelmente consequência de aquela taxa ter sido utilizada (indiretamente) para compatibilizar o modelo deles com a carga tributária agregada observada, compensando em parte o valor significativamente mais baixo do que os outros estudos para $\tau^{c}$.

${ }^{27}$ Fontes: IBGE (2018), Tabela Sinótica 1, e BCB (2018) - série histórica da taxa de juros implícita DLSP e DBGG - TXIMPLNP.

${ }^{28}$ Bezerra et al. (2014) encontram, para 2010, taxa real bruta sobre os títulos da dívida pública igual a 6,92\% a.a., carga tributária média ponderada pelos vencimentos de $17,05 \%$ e uma taxa líquida de $5,74 \%$ a.a. 
Quadro 1 - Parâmetros da calibração para o Brasil

\begin{tabular}{|c|c|c|}
\hline Símbolo & Descrição & Valor \\
\hline$\beta$ & Fator de desconto intertemporal & 0,9241 \\
\hline$\sigma$ & Aversão relativa ao risco da função utilidade CRRA & 2 \\
\hline$\vartheta$ & Parâmetro de substituição entre consumo privado e público & 0,1 \\
\hline$\gamma$ & Peso do consumo na função utilidade & 0,3432 \\
\hline$\gamma_{n}$ & Fator de crescimento da população & 1,0086 \\
\hline$\gamma_{z}$ & Fator crescimento da produtividade da mão de obra & 1,02 \\
\hline$Z_{0}$ & Nível inicial da produtividade da mão de obra & 1 \\
\hline$h$ & Fração da dotação de horas que é alocada a trabalho & 0,24 \\
\hline$i / y$ & Razão investimento privado/produto & 0,16 \\
\hline$c / y$ & Razão consumo privado/produto & 0,62 \\
\hline$k / y$ & Razão capital/produto & 2,52876 \\
\hline$k^{g} / y$ & Razão capital público/produto & 0,3161 \\
\hline$a_{1}$ & Elasticidade do capital privado na produção & 0,392 \\
\hline$a_{2}$ & Elasticidade do trabalho na produção & 0,588 \\
\hline$a_{3}$ & Elasticidade do capital público na produção & 0,02 \\
\hline$\delta^{p}$ & Depreciação do capital privado & 0,0345 \\
\hline$\delta^{g}$ & Depreciação do capital público & 0,0345 \\
\hline$g^{c} / y$ & Razão consumo do governo/produto & 0,20 \\
\hline$g^{i} / y$ & Razão investimento do governo/produto & 0,02 \\
\hline$g^{t r} / y$ & Razão transferências do governo/produto no estado estacionário & 0,01759 \\
\hline$\tau^{c}$ & Alíquota do tributo sobre consumo & 0,1902 \\
\hline$\tau^{l}$ & Alíquota do tributo sobre renda do trabalho & 0,2171 \\
\hline$\tau^{k}$ & Alíquota do tributo sobre renda do capital & 0,13 \\
\hline$b / y$ & Razão dívida pública/produto no estado estacionário & 0,66 \\
\hline$r^{b}$ & Retorno real dos títulos públicos & 0,06 \\
\hline
\end{tabular}

A razão entre as transferências do governo para as famílias e o produto $\left(g^{t r} / y=1,76 \%\right)$ foi calibrada para ser consistente com o EE, isto é, para resolver o sistema de Equações (17) a (24). Um valor superior ao indicado, resultante de uma política fiscal não sustentável, produziria uma trajetória explosiva de dívida. O Quadro 1 sintetiza os parâmetros adotados na calibração do modelo. 


\subsection{Simulações de Mudanças de mix Fiscal}

As simulações de alteração do mix fiscal são feitas a partir do EE inicial indicado na subseção anterior, alterando um dos parâmetros fiscais e compensando-a com a modificação de outro parâmetro, de modo que a restrição orçamentária intertemporal e as demais equações do modelo sejam satisfeitas. ${ }^{29}$ Cada política é caracterizada pelo par de parâmetros envolvidos nela, cujos valores são mantidos constantes por todo o horizonte. Os outros parâmetros fiscais são mantidos constantes no nível do EE, inclusive a razão dívida pública/produto. O conjunto de simulações para diferentes pares de instrumentos produz um mapa conceitual dos impactos relativos de diferentes políticas. Para tornar comparáveis os resultados de cada uma das simulações, a alteração da alíquota do imposto $\left(\tau_{t}^{c}, \tau_{t}^{l}, \tau_{t}^{k}\right)$ ou do dispêndio por unidade de trabalho eficiente $\left(g_{t}^{c}, g_{t}^{t r}, g_{t}^{i}\right)$ que a caracteriza é calibrada para corresponder a uma alteração de receita ou despesa de $1 \%$ do PIB do EE inicial. Como a compensação é calculada para manter o orçamento equilibrado, as mudanças de mix fiscal têm efeito nulo sobre $b / y$.

Esses exercícios podem ser analisados sob duas perspectivas complementares: i) o impacto das alterações no EE, calculando a solução do sistema de Equações (17)-(24), mostrado na Tabela 2; e ii) o efeito no comportamento dinâmico da economia na transição entre esses dois estados estacionários resolvendo o sistema de Equações (9)-(16) para cada data, até o final do horizonte. Evidentemente, a trajetória dinâmica tem que convergir para o EE se for considerado um horizonte de tempo suficientemente longo. Como as trajetórias até este novo EE são suaves, e quase todas elas monotônicas, o efeito no EE contém toda a informação relevante quanto aos efeitos das mudanças de mix fiscal e, portanto, a discussão abaixo se baseia na Tabela 2. Ela mostra um conjunto de dezessete simulações, em colunas agrupadas de acordo com o instrumento de política indicado na primeira linha. Para cada um deles, o instrumento de compensação é indicado no topo da coluna correspondente em pontos percentuais (p.p.) no caso das alíquotas dos tributos, e em variação percentual relativamente ao EE no caso das transferências $\left(g^{t r}\right)$. Os valores elevados da variação de $g^{t r}$ correspondem de fato a variações pequenas relativamente ao produto $(y)$, pois a razão $g^{t r} / y$ no EE inicial é $1,8 \% .{ }^{30}$ As diferentes políticas podem ser ordenadas quanto

\footnotetext{
${ }^{29}$ É usual na simulação de modelos de equilíbrio geral partir de um estado estacionário, para que os efeitos da política extraídos do modelo reflitam as suas características estruturais.

${ }^{30}$ Por exemplo, uma redução de $0,9 \%$ de $y$ corresponde a $-50 \%$ de $g^{t r}$.
} 
à magnitude do seu efeito sobre os diferentes agregados macroeconômicos examinando a linha correspondente na Tabela 2, como se faz a seguir.

Tabela 2 - Efeitos no estado estacionário de alterações no mix gasto-tributação ${ }^{1}$

\begin{tabular}{|c|c|c|c|c|c|c|c|c|c|}
\hline Política $^{2} \rightarrow$ & \multicolumn{3}{|c|}{ Redução de $\tau^{1}$} & \multicolumn{3}{|c|}{ Redução de $\tau^{\mathrm{k}}$} & \multicolumn{3}{|c|}{ Redução de $\tau^{\mathrm{c}}$} \\
\hline Compensação $\rightarrow$ & $\mathrm{g}^{\mathrm{tr}}$ & $\tau^{c}$ & $\tau^{\mathrm{k}}$ & $g^{\operatorname{tr}}$ & $\tau^{c}$ & $\tau^{1}$ & $g^{\operatorname{tr}}$ & $\tau^{1}$ & $\tau^{\mathrm{k}}$ \\
\hline Variação compensatória $^{3}$ & -37.06 & 1.332 & 3.321 & -29.82 & 1.037 & 1.330 & -44.93 & 2.072 & 4.031 \\
\hline$y$ & 1.293 & 0.621 & -0.754 & 1.526 & 1.000 & 0.489 & 0.819 & -0.784 & -1.656 \\
\hline$c$ & 1.751 & 0.842 & -0.255 & 1.475 & 0.765 & 0.076 & 1.109 & -1.063 & -1.320 \\
\hline$h$ & 1.337 & 0.643 & 1.251 & 0.073 & -0.463 & -0.983 & 0.847 & -0.811 & 0.748 \\
\hline$i$ & 1.293 & 0.621 & -3.724 & 3.826 & 3.288 & 2.765 & 0.819 & -0.784 & -5.235 \\
\hline$k$ & 1.293 & 0.621 & -3.724 & 3.826 & 3.288 & 2.765 & 0.819 & -0.784 & -5.235 \\
\hline$w$ & -0.044 & -0.021 & -1.980 & 1.452 & 1.470 & 1.487 & -0.028 & 0.027 & -2.386 \\
\hline$r^{k}$ & -0.000 & -0.000 & 3.085 & -2.215 & -2.215 & -2.215 & -0.000 & -0.000 & 3.777 \\
\hline$\xi$ & 0.876 & 0.424 & -1.000 & 1.384 & 1.023 & 0.669 & 0.558 & -0.544 & -1.724 \\
\hline Política $^{2} \rightarrow$ & \multicolumn{4}{|c|}{ Aumento de $\mathrm{g}^{\mathrm{c}}$} & \multicolumn{5}{|c|}{ Aumento de $\mathrm{g}^{\mathbf{i}}$} \\
\hline Compensação $\rightarrow$ & $g^{\text {tr }}$ & $\tau^{c}$ & $\tau^{1}$ & $\tau^{\mathrm{k}}$ & $g^{\text {tr }}$ & $\tau^{\mathrm{c}}$ & & $\tau^{1}$ & $\tau^{\mathrm{k}}$ \\
\hline Variação compensatória $^{3}$ & -54.32 & 2.030 & 2.603 & 5.093 & -36.77 & 1.29 & & 1.661 & 3.235 \\
\hline$y$ & 0.841 & -0.16 & -1.155 & -2.271 & 2.026 & 1.37 & & 0.738 & 0.033 \\
\hline$c$ & -0.474 & -1.83 & -3.178 & -3.526 & 1.132 & 0.24 & & 0.613 & -0.815 \\
\hline$h$ & 0.869 & -0.168 & -1.194 & 0.775 & 0.697 & 0.03 & & 0.617 & 0.629 \\
\hline$i$ & 0.841 & -0.162 & -1.155 & -6.777 & 2.026 & 1.37 & & 0.738 & -2.882 \\
\hline$k$ & 0.841 & -0.162 & -1.155 & -6.777 & 2.026 & 1.37 & & 0.738 & -2.882 \\
\hline$w$ & -0.028 & 0.006 & 0.040 & -3.022 & 1.320 & 1.34 & & 1.363 & -0.592 \\
\hline$r^{k}$ & -0.000 & -0.000 & -0.000 & 4.834 & -0.000 & -0.00 & & 0.000 & 3.002 \\
\hline$\xi$ & -0.826 & $-1.52 C$ & -2.220 & -3.712 & 0.671 & 0.22 & & 0.223 & -1.167 \\
\hline
\end{tabular}

Notas: ${ }^{1}$ Porcentagem da variação em relação ao estado estacionário inicial. ${ }^{2}$ A variação do instrumento de política é tal que o valor do acréscimo de receita ou redução da despesa seja de $1 \%$ do PIB no estado estacionário. ${ }^{3} \mathrm{~A}$ variação do instrumento de compensação é apresentada em p.p. para as alíquotas dos tributos, e como variação percentual relativamente ao estado estacionário, para as transferências.

As duas políticas que têm maior efeito sobre o produto $(y)$ são: $i)$ redução dos gastos de consumo do governo $\left(\mathrm{g}^{\mathrm{c}}\right)$ em $1 \%$ do produto, associada a uma redução de 5,1 p.p. na alíquota de tributação sobre o capital, o que aumenta $y$ no EE em 2,3\%; ${ }^{31}$ e ii) aumento do investimento do governo (gi) em $1 \%$ do PIB, financiado pela redução das transferências em $36,7 \%$, o que aumenta $y$ no EE em 2,0\%. Há quatro outras políticas cujo efeito sobre $y$ no EE está entre $1,3 \%$ e $1,6 \%$.

As duas políticas que têm maior efeito sobre o sobre o consumo $(c)$ correspondem à redução dos gastos de consumo do governo $\left(\mathrm{g}^{\mathrm{c}}\right)$ em $1 \%$ do

${ }^{31}$ Noteque, na Tabela 2, ovalor correspondente ao efeito desta combinação de instrumentos sobre o produto é negativo, porque a política indicada corresponde a um aumento de $\mathrm{g}^{\mathrm{C}}$ associado a um aumento de $\tau^{k}$. 
produto associada a uma redução de 5,1 p.p. na alíquota do imposto sobre a renda do capital $\left(\tau^{k}\right)$ ou a uma redução de 2,6 p.p. na alíquota do imposto sobre a renda do trabalho $(\tau l)$, que aumentam $c$ no EE em, respectivamente, $3,5 \%$ e $3,1 \% .{ }^{32}$ Todavia, há quatro outras políticas cujo efeito sobre $c$ no EE está entre 1,3\% e 1,8\%. Como se poderia esperar, as políticas que mais afetam o consumo são também aquelas que têm maior efeito sobre o índice de bem-estar $(\zeta)$.

O efeito no estoque de capital $(k)$ e no investimento $(i)$, no EE, das diferentes políticas são iguais, em decorrência da Equação (18), que especifica uma relação linear entre estas variáveis. As duas políticas que têm maior impacto sobre elas são: i) redução dos gastos de consumo do governo $\left(\mathrm{g}^{\mathrm{c}}\right)$ em $1 \%$ do PIB, associada a uma redução de 5,1 p.p. na alíquota de tributação sobre o capital, que resulta em um aumento de $k$ e $i$ no EE de 6,7\%; e ii) o aumento da alíquota do imposto sobre o consumo $\left(\tau^{c}\right)$ suficiente para aumentar sua arrecadação em $1 \%$ do produto, compensada por uma redução de 4 p.p. da alíquota do imposto sobre a renda do capital $\left(\tau^{k}\right)$, que resulta em um aumento $k$ e $i$ no EE de 5,2\%. Há quatro outras políticas com efeito sobre $k$ e $i$ no EE entre 2,0\% e 3,7\%. As políticas que mais afetam a taxa de retorno sobre o capital privado $\left(r^{k}\right)$ e o salário $(w)$ são as mesmas que mais afetam $k$ e $i$. É também importante notar que a taxa de retorno sobre o capital privado só é afetada por políticas que alteram $\tau{ }^{k}$, pois este é o único instrumento fiscal que aparece na Equação (17).

Em síntese, uma mudança de mix fiscal reduzindo gastos do governo $\left(\mathrm{g}^{\mathrm{c}}\right) \mathrm{e}$ o imposto sobre a renda do capital $\left(\tau^{k}\right)$, é o que produz o maior impacto em $y, c, i, k, w e r^{k}$. No caso específico do efeito sobre consumo (c) e bem-es$\operatorname{tar}(\xi)$ a redução de $\mathrm{g}^{\mathrm{c}}$ acompanhada de uma redução de $\tau^{l}$, produz efeito apenas um pouco menor do que o da redução de $\tau^{k}$.

\subsection{Simulações de Consolidação da Dívida}

Seguindo Papageorgiou (2012), as políticas fiscais abordadas nesta subseção visam reduzir a dívida pública em $10 \%$ nos dez primeiros anos após a sua implantação, denominado período de ajustamento, e permitir que depois

\footnotetext{
${ }^{32}$ Note que, na Tabela 2, o valor correspondente ao efeito dessas combinações de instrumentos sobre o produto é negativo, porque as políticas indicadas correspondem a um aumento de $\mathrm{g}^{\mathrm{c}}$ associado a um aumento de $\tau^{k}$ ou de $\tau l$.
} 
disso ela siga uma trajetória sustentável no longo prazo. ${ }^{33} \mathrm{O}$ exercício aqui é feito no contexto determinístico do modelo e, portanto, considera-se que, no instante inicial, o governo se compromete com toda a trajetória futura dos instrumentos fiscais, e os agentes econômicos fazem seus planos no instante inicial, tomando-as como dadas. Faz-se uma simulação para cada instrumento fiscal: as três alíquotas de impostos e dois tipos de dispêndio público. ${ }^{34} \mathrm{~A}$ análise aqui é complementar à da subseção anterior, no sentido de simular a resposta da economia a diferentes tipos de política fiscal: lá utilizamos diferentes combinações de dois instrumentos (mix fiscal) cujos níveis são mantidos constantes por todo o período de análise, enquanto nesta subseção examinamos trajetórias que envolvem variações do nível de um mesmo instrumento nos dois subperíodos indicados acima.

Supondo que a economia esteja no EE inicial, o governo altera o valor de um dos instrumentos fiscais (alíquota de um imposto ou nível de um dispêndio) e ele é mantido constante ao longo do subperíodo de estabilização $(t=0,1, \ldots, 10)$. Isso visa que ao final daquele subperíodo a dívida pública tenha sido reduzida em 10\%, e o valor do instrumento fiscal é calculado endogenamente para atingir aquele objetivo. Em seguida, inicia-se o segundo subperíodo $(t=11, \ldots, 200)$, ao longo do qual o instrumento fiscal toma um novo valor, também calculado endogenamente para satisfazer a restrição do orçamento intertemporal do governo. Isso faz a dívida convergir para o seu novo EE. Em cada simulação, os valores dos demais instrumentos fiscais são mantidos no mesmo nível que tinham no EE anterior à consolidação.

O Gráfico 1 mostra a trajetória da economia para as consolidações baseadas em instrumentos tributários: alíquota do imposto sobre a renda do trabalho $\left(\tau^{l}\right)$, renda do capital $\left(\tau^{k}\right)$, e consumo privado $\left(\tau^{c}\right)$. O Gráfico 2 mostra a trajetória da economia para as consolidações baseadas em dispêndio consumo do governo $\left(g^{c}\right)$ e investimento do governo $\left(g^{i}\right)$. O modelo é resolvido para duzentos períodos, mas só os cinquenta primeiros são apresentados, admitindo que, nesse prazo, quase todo o efeito de longo prazo já tenha materializado e, por limitações de espaço, são apresentadas apenas as trajetórias para $y, c, h, k$ e $d / y$.

${ }^{33}$ É importante notar que a simulação é para uma redução do nível de dívida (b), e que a trajetória resultante da razão dívida-produto $(b / y)$ depende da trajetória do produto $(y)$, que é endógena.

${ }^{34}$ As transferências $\left(g^{t r}\right)$ são mantidas constantes no nível inicial, consistente com o equilíbrio de longo prazo, pois este parâmetro foi o escolhido como a variável de ajuste do modelo. 
A Tabela 3 sintetiza os pontos críticos dessas trajetórias, apresentando um par de colunas para cada instrumento, que é indicado na primeira linha. A primeira coluna do par mostra o impacto inicial (em $t=1$ ) e a segunda mostra o efeito em $t=50$. A penúltima linha da tabela indica o valor do instrumento nos dois subperíodos, e a última linha mostra o valor do índice de bem-estar referente a toda a trajetória da consolidação, calculado de acordo com a Equação (25). Tanto na Tabela 3 quanto nos Gráficos 1 e 2 os resultados das simulações são apresentados como desvios percentuais em relação ao equilíbrio pré-reforma para todas as variáveis, exceto para a razão deficit público/produto $(d / y)$ e as alíquotas dos impostos $\left(\tau^{l}, \tau^{c}, \tau^{k}\right)$ que são em p.p.

Tabela 3 - Impacto e efeito de longo prazo de consolidações fiscais

\begin{tabular}{|c|c|c|c|c|c|c|c|c|c|c|}
\hline \multirow{2}{*}{$\begin{array}{c}\text { Instrumento } \\
\text { Variável }\end{array}$} & \multicolumn{2}{|c|}{$\begin{array}{c}\tau^{l} \\
\text { Imposto sobre } \\
\text { trabalho }\end{array}$} & \multicolumn{2}{|c|}{$\begin{array}{c}\tau^{c} \\
\text { Imposto sobre } \\
\text { consumo }\end{array}$} & \multicolumn{2}{|c|}{$\begin{array}{c}\tau^{k} \\
\text { Imposto sobre } \\
\text { capital }\end{array}$} & \multicolumn{2}{|c|}{$\begin{array}{c}g^{c} \\
\text { Consumo } \\
\text { governo }\end{array}$} & \multicolumn{2}{|c|}{$\begin{array}{c}g^{i} \\
\text { Investimento } \\
\text { governo }\end{array}$} \\
\hline & Impacto & $\begin{array}{l}\text { Longo } \\
\text { prazo }\end{array}$ & Impacto & $\begin{array}{l}\text { Longo } \\
\text { prazo }\end{array}$ & Impacto & $\begin{array}{l}\text { Longo } \\
\text { prazo }\end{array}$ & Impacto & $\mid \begin{array}{l}\text { Longo } \\
\text { prazo }\end{array}$ & Impacto & $\begin{array}{r}\text { Longo } \\
\text { prazo }\end{array}$ \\
\hline$y$ & $-0,78$ & 0,74 & $-0,27$ & 0,56 & $-0,17$ & 1,18 & $-0,19$ & 0,49 & $-0,18$ & 1,24 \\
\hline$c$ & $-0,66$ & 1,00 & $-0,42$ & 0,75 & 0,22 & 1,14 & 0,32 & $-0,28$ & 0,23 & 0,66 \\
\hline$h$ & $-1,32$ & 0,77 & $-0,46$ & 0,57 & $-0,29$ & 0,061 & $-0,33$ & 0,51 & $-0,31$ & 0,45 \\
\hline$i$ & $-2,30$ & 0,75 & $-0,053$ & 0,55 & $-1,87$ & 2,96 & 0,30 & 0,49 & 0,82 & 1,30 \\
\hline$k$ & 0 & 0,73 & 0 & 0,56 & 0 & 2,95 & 0 & 0,49 & 0 & 1,16 \\
\hline$w$ & 0,55 & $-0,031$ & 0,19 & $-0,017$ & 0,12 & 1,12 & 0,14 & $-0,015$ & 0,13 & 0,78 \\
\hline$r^{k}$ & $-0,78$ & 0,001 & $-0,27$ & 0 & $-0,17$ & $-1,71$ & $-0,19$ & $-0,002$ & $-0,18$ & 0,072 \\
\hline$d / y$ & $-1,41$ & 0,95 & $-1,12$ & 1,30 & $-1,13$ & 1,25 & $-1,07$ & 1,35 & $-1,10$ & 1,06 \\
\hline$b / y$ & 0,78 & $-7,4$ & 0,27 & $-10,6$ & 0,17 & $-7,8$ & 0,19 & $-11,2$ & 0,18 & $-7,7$ \\
\hline Instru-mento & 1,25 & $-0,97$ & 0,89 & $-1,10$ & 1,27 & $-1,98$ & $-2,18$ & 2,91 & $-23,0$ & 30,9 \\
\hline$\zeta$ & \multicolumn{2}{|c|}{$-0,1091$} & \multicolumn{2}{|c|}{0,0318} & \multicolumn{2}{|c|}{0,0684} & \multicolumn{2}{|c|}{0,0122} & \multicolumn{2}{|c|}{0,0082} \\
\hline
\end{tabular}

Nota: Os valores na tabela são desvios percentuais do equilíbrio pré-reforma para todas as variáveis, exceto o deficit público primário sobre produto e as alíquotas de tributação, que estão em p.p.

\subsubsection{Políticas Baseadas em Impostos}

Nesse caso, as alíquotas dos impostos aumentam no primeiro subperíodo e depois se reduzem, ambos relativamente ao estado estacionário inicial, de tal modo que o deficit público primário $(d / y)$ se reduz no primeiro subperíodo e aumenta no segundo, como se vê nas trajetórias na última linha do Gráfico 1. A redução inicial é necessária para reduzir a dívida, e 
o aumento subsequente é possível principalmente devido à redução do pagamento de juros sobre a dívida pública. Em valor absoluto, o efeito sobre $d / y$ no primeiro subperíodo é maior, e no segundo subperíodo é menor, quando a consolidação é baseada em $\tau^{l}$ do que quando ela é baseada em $\tau^{c}$ ou $\tau^{k}$, pois o modelo considera tanto o efeito direto quanto o indireto dos tributos.

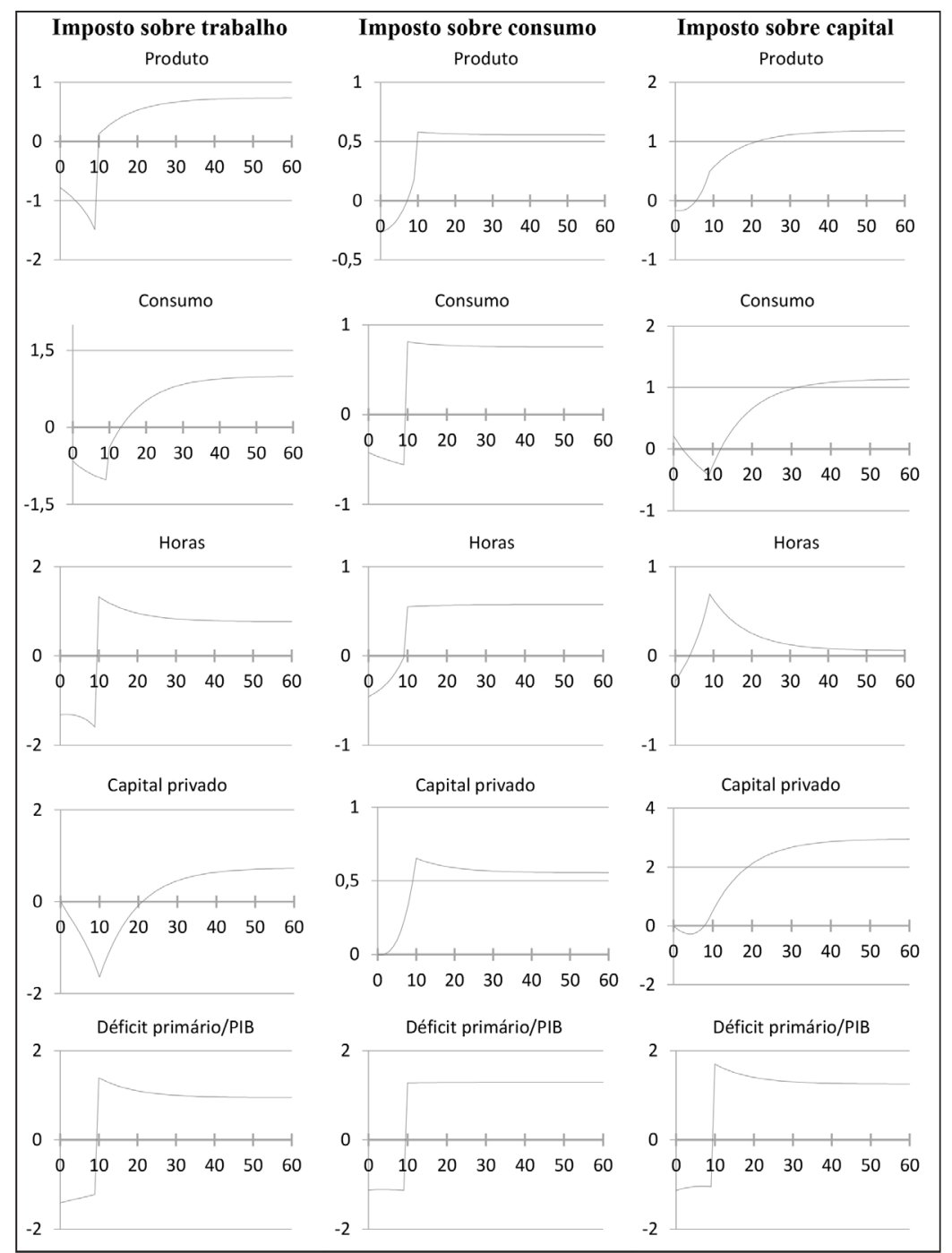

Gráfico 1 - Brasil: dinâmica das consolidações fiscais baseadas em impostos

Nota: Os valores na tabela são desvios percentuais do equilíbrio pré-reforma para todas as variáveis, exceto o deficit público primário sobre produto que está em p.p. 
A seguir, comparamos os efeitos sobre o lado real de economia. A primeira linha da Tabela 3 mostra os efeitos sobre o produto, onde se verifica que a consolidação baseada em $\tau^{k}$ tem um impacto menor, mas um efeito positivo maior no longo prazo do que as outras. A comparação entre as políticas baseadas em $\tau^{c}$ e $\tau^{l}$ é menos óbvia, pois a primeira tem um impacto menor, mas traz um ganho menor no longo prazo do que a segunda. No entanto, este é um caso no qual o impacto não é representativo do efeito ao longo do período de ajustamento. O Gráfico 1 mostra que a política baseada em $\tau^{l}$ é claramente inferior à baseada em $\tau^{c}$ na estabilização, pois o seu efeito negativo sobre o produto é maior (em valor absoluto) do que o seu impacto imediato, e dura até $\mathrm{t}=10$. Por outro lado, na consolidação, a política baseada em $\tau^{l}$ é um pouco melhor do que a baseada em $\tau^{c}$ porque seu efeito de longo prazo é maior, como se vê na Tabela 3. No entanto, em termos de valor presente, esta vantagem não é suficiente para compensar a desvantagem quanto ao impacto de curto prazo, indicando o seguinte ordenamento dos instrumentos quanto ao efeito em $y: \tau^{k}>\tau^{c}>\tau^{l}$. Através de análise similar verifica-se que mesma ordenação também vale para o consumo $(C)$.

$\mathrm{Na}$ Tabela 3 verifica-se que o efeito sobre o estoque de capital $(k)$ no longo prazo da consolidação baseada em $\tau^{k}$ é bem maior do que nas baseadas em $\tau^{l}$ e $\tau^{c}$. Como o impacto de todas elas em $k$ é nulo, pois ele é medido no início de cada $t$, o desempenho relativo delas no período de estabilização precisa ser avaliado com auxílio do Gráfico 1. Na quarta linha, verifica-se que no primeiro subperíodo o efeito de $\tau^{l}$ é negativo e crescente em valor absoluto, chegando a $-1,8 \%$, enquanto o de $\tau^{c}$ é positivo e crescente, chegando a $+0,5 \%$ no final da estabilização. O efeito de $\tau^{k}$ durante a estabilização é apenas ligeiramente negativo, tornando-se positivo ao final. Entretanto, o efeito maior da política baseada em $\tau^{l}$ no segundo subperíodo é insuficiente para compensar a desvantagem dela frente às outras políticas durante a estabilização. Portanto, ordenamento dos instrumentos quanto efeito em é o mesmo encontrado quanto a $y$ e $C$.

O efeito dessas políticas sobre o investimento $(i)$ é consequência do efeito sobre a variação líquida do estoque de capital - vide Equação (12) - e no longo prazo é proporcional a ele - Equação (18). As linhas correspondentes a essas variáveis na Tabela 3 mostram que o efeito dessas políticas sobre estes agregados é virtualmente idêntico em cada simulação. 
$\mathrm{Na}$ Tabela 3 verifica-se que os efeitos de longo prazo sobre a taxa de retorno sobre o capital privado $\left(r^{k}\right)$ e sobre o salário $(w)$ das políticas baseadas em $\tau^{c}$ e $\tau^{l}$ não afetam $r^{k}$ nem $w$. Já a baseada em $\tau^{k}$ reduz $r^{k}$ em $1,7 \%$, e aumenta $w$ em $1,1 \%$.

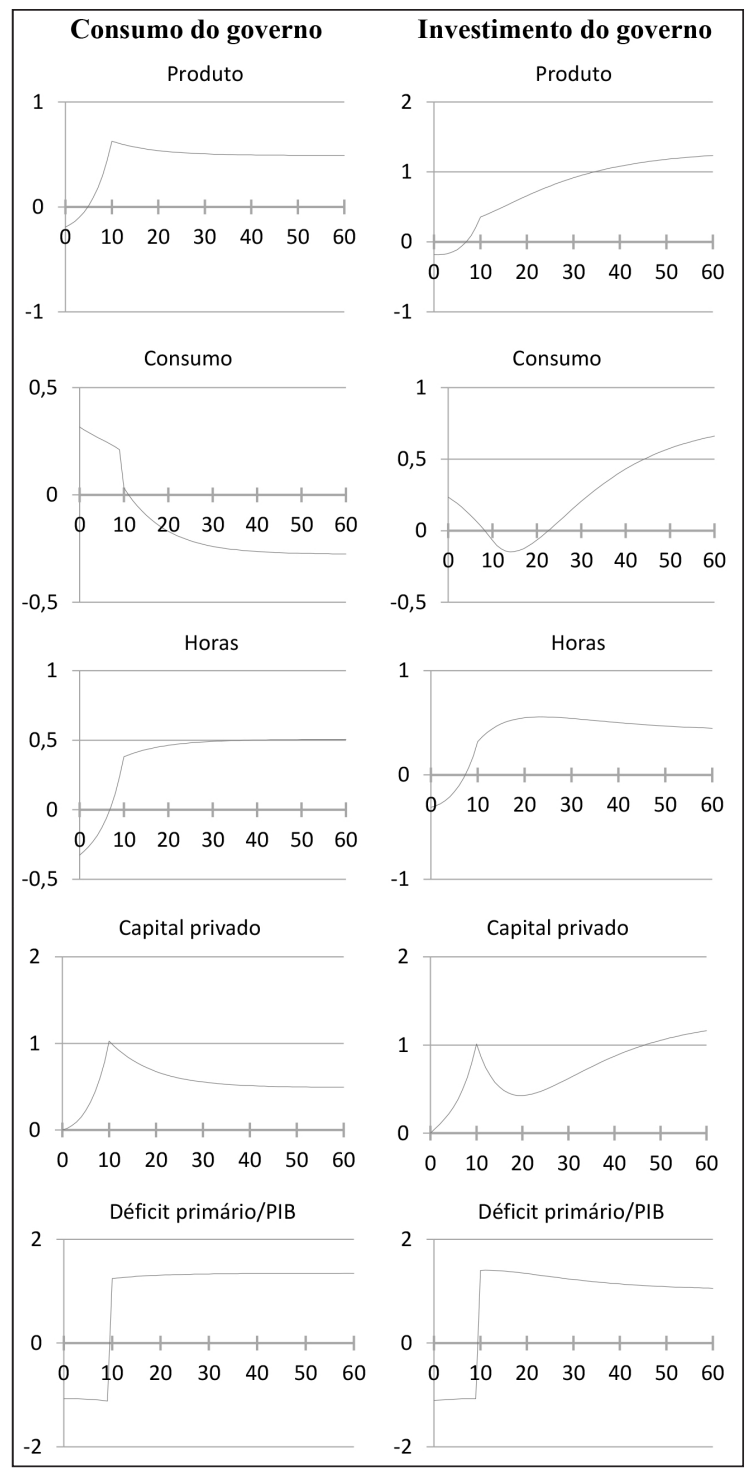

Gráfico 2 - Brasil: dinâmica das consolidações fiscais baseadas em dispêndio Nota: Os valores na tabela são desvios percentuais do equilíbrio pré-reforma para todas as variáveis, exceto o deficit público primário sobre produto que está em p.p. 


\subsubsection{Políticas Baseadas em Dispêndio}

As duas outras simulações de consolidação fiscal usam como instrumento o consumo e o investimento do governo ( $g^{c}$ e $g^{i}$ respectivamente). Os seus resultados aparecem no quarto e quinto par de colunas da Tabela 3, e no Gráfico 2. A penúltima linha da tabela mostra a variação dos seus níveis em relação àqueles do EE nos dois subperíodos. ${ }^{35} \mathrm{O}$ efeito sobre o deficit público primário $(d / y)$ das políticas baseadas nestes dois instrumentos é da mesma magnitude, mas o efeito no longo prazo é um pouco maior no caso da consolidação baseada em $g^{c}$ do que naquela baseada em $g^{i}$.

A primeira linha da Tabela 3 mostra que o impacto sobre o produto dessas duas políticas sobre o produto é aproximadamente o mesmo, mas o efeito no longo prazo da política baseada em $g^{i}$ é 2,5 vezes maior do que o da baseada em $g^{c}$. Entretanto, o impacto não pode ser tomado como representativo do efeito ao longo da estabilização, o qual precisa ser analisado com auxílio do Gráfico 2, que mostra na sua primeira linha que o efeito de $g^{c}$ em $y$ é positivo já a partir de $t=4$, e que o efeito de longo prazo já está presente em $t=10$, enquanto o efeito de $g^{i}$ em $y$ só se torna positivo a partir de $t=7$, e só ultrapassa $1,0 \%$ em torno de $t=35$. Portanto, os efeitos do investimento público sobre o produto são maiores do que os do consumo público, mas demoram mais a se manifestar, como se poderia esperar.

O impacto no consumo privado (c) dessas duas políticas é a mesma ordem de grandeza, e o seu efeito declina progressivamente ao longo do primeiro subperíodo até se anular ao final (segunda linha do Gráfico 2). No entanto, o efeito de longo prazo delas é muito diferente. A consolidação baseada em $g^{c}$ leva a um decréscimo de $c$ ao longo de todo segundo subperíodo, chegando a um valor negativo ao final dele. Isto é consequência da substituição entre $c$ e $g^{c}$ na função utilidade, representada pela Equação (9). Já a consolidação baseada em $g^{i}$ permite uma recuperação do consumo a partir de $t=15$, e seu aumento progressivo a partir de $t=32$, o que mostra que ela é melhor. Esse crescimento do consumo é consequência do aumento do estoque de capital público - Equação (13) - e do efeito dele na produção - Equação (14).

\footnotetext{
${ }^{35}$ No caso de $g^{i}$, os valores elevados da variação relativa correspondem a variações pequenas com relação ao produto $(y)$, pois a razão $g^{i} / y$ no EE inicial é $2,0 \%$. Por exemplo, uma redução de $1 \%$ de $y$ corresponde a uma variação de $-50 \%$ em $g^{i}$.
} 
Examinando o efeito sobre o estoque de capital privado no longo prazo na Tabela 3, verifica-se que o efeito da política baseada em $g^{c}$ é ligeiramente maior que a metade daquele da política baseada em $g^{i}$. A quarta linha do Gráfico 2 mostra que a trajetória nesses dois casos é muito similar na estabilização, e no início do segundo subperíodo, até $t=15$. Porém, a partir daí, a dinâmica é bastante diferente: enquanto no primeiro caso o efeito se estabiliza, no segundo ele é crescente. Como no caso das políticas baseadas em impostos, o efeito sobre o investimento $(i)$ é consequência do efeito sobre a variação líquida do estoque de capital e, no longo prazo, é proporcional a ele. As linhas correspondentes a estas variáveis na Tabela 3 mostram que o efeito destas políticas é muito similar nas duas simulações.

As políticas baseadas em $g^{c}$ e $g^{i}$ têm o mesmo impacto sobre a taxa de retorno do capital $r^{k}$, e o efeito de longo prazo delas é muito pequeno. O impacto delas sobre o salário $w$ também é idêntico e pequeno, mas o efeito de longo prazo é diferenciado: ele não é afetado pela política baseada em $g^{c}$, mas é positivamente afetado pela baseada em $g^{i}$. Isto também é esperado, na medida em que o aumento do estoque de capital público aumenta a produtividade do trabalho.

\subsubsection{Sintese dos Efeitos das politicas de consolidação da dívida}

Os dois tipos de política fiscal foram discutidos nas duas seções precedentes, e o seu ordenamento quanto aos seus efeitos sobre os níveis $y, c$ e $k$, levando em conta tanto o impacto de curto prazo quanto o efeito de longo prazo é: $\tau^{k}>\tau^{c}>\tau^{l}$ e $g^{i}>g^{c}$, para as políticas baseadas em tributos e em dispêndio público, respectivamente. A seguir comparamos os efeitos dos cinco instrumentos no longo prazo sem agregá-los por tipo.

As cinco políticas levam à redução da razão dívida pública/produto entre $7,4 \%$ e $11,1 \%$ (linha $d / y$ da Tabela 3 ). O ordenamento de seus efeitos sobre os níveis dos agregados no longo prazo na Tabela 3 permite comparar os dois tipos de instrumentos: i) para $y: g^{i}>\tau^{k}>\tau^{l}>\tau^{c}>g^{c}$; ii) para $c: \tau^{k}>\tau^{l}>\tau^{c}>g^{i}>g^{c}$; iii) para $k: \tau^{k}>g^{l}>\tau^{l}>\tau^{c}>g^{c}$. Verifica-se que o ordenamento indicado acima dentro dos tipos de política é preservado, que a política baseada no consumo do governo $\left(g^{c}\right)$ é a que tem menor impacto positivo nos três agregados, e que a política baseada em $\tau^{k}$ é a que tem o maior efeito sobre o consumo e capital privado, e segundo maior 
efeito sobre o produto. A política baseada em investimento do governo $\left(g^{i}\right)$ também tem bons resultados sobre $y$ e $k$.

No entanto, a comparação mais relevante é quanto ao índice de bem-estar $(\xi)$, que leva em conta explicitamente a utilidade marginal decrescente do consumo de bens privados e públicos, a desutilidade do trabalho, e o desconto intertemporal (Equação (1)) além de indicar a ordem de preferência social no uso dos instrumentos fiscais. Como se verifica da última linha da Tabela 3, essa preferência é: $\tau^{k}>\tau^{c}>g^{c}>g^{i}>\tau^{l}$. A melhor delas é a baseada no imposto sobre a renda do capital $\left(\tau^{k}\right)$, que equivale a um acréscimo de $0,07 \%$ do consumo per capita em cada ano da trajetória. A pior delas é a baseada no imposto sobre a renda do trabalho $\left(\tau^{l}\right)$, com efeito equivalente a uma redução de $0,11 \%$ do consumo per capita em cada ano da trajetória.

\section{Conclusão}

Este trabalho avaliou diferentes políticas fiscais com o auxílio do modelo dinâmico de equilíbrio geral proposto por Papageorgiou (2012) calibrado para a economia brasileira. $\mathrm{O}$ modelo foi empregado para simular o estado estacionário e a transição para alcançá-lo quando o mix fiscal é alterado, e também quando se empregam diferentes estratégias de consolidação da dívida pública baseadas em um dos instrumentos. Faz-se a comparação entre elas examinando seus efeitos sobre os principais agregados macroeconômicos e sobre um índice de bem-estar que é função do valor presente da utilidade do consumo per capita futuro.

As simulações de mix fiscal foram feitas alterando um dos parâmetros fiscais e compensando-o com a modificação de outro parâmetro, mantendo inalterado o endividamento de longo prazo. Cada política é caracterizada pelo par de parâmetros envolvidos nela, cujos valores são mantidos constantes por todo o horizonte, e as simulações são comparáveis, envolvendo o mesmo esforço fiscal. Os resultados mostram que uma mudança de mix fiscal reduzindo gastos do governo e o imposto sobre a renda do capital é a que produz o maior impacto positivo no produto, consumo, bem-estar, investimento, estoque de capital, e salário no estado estacionário. 
As estratégias de consolidação da dívida visam reduzir a dívida pública em $10 \%$ em dez anos, cada uma usando apenas um instrumento fiscal. O seu valor é mantido constante durante o período de estabilização, e ele adota um novo valor (também constante) até o final do horizonte. O valor deles em cada um destes subperíodos é determinado endogenamente. As estratégias aqui consideradas envolvem desvios de sinal contrário no período de estabilização e pós-estabilização: os impostos aumentam no curto prazo e se reduzem no longo, e os dispêndios públicos se reduzem no curto prazo e aumentam no longo. Comparando o efeito de longo prazo destas políticas fiscais, verifica-se que a baseada no consumo do governo $\left(g^{c}\right)$ tem o menor efeito positivo em $y, c$ e $k$, e a baseada no imposto sobre a renda do capital $\left(\tau^{k}\right)$ tem o maior efeito sobre o $c$ e $k$ e o segundo maior efeito sobre $y$. Em vários casos o imposto sobre a renda do trabalho $\left(\tau^{l}\right)$ tem efeito apenas um pouco menor do que $\left(\tau^{k}\right)$. A política baseada em investimento do governo $\left(g^{i}\right)$ também tem bons resultados sobre $y$ e $k$. Sob o ponto de vista do índice de bem estar, a melhor e pior política são baseadas, respectivamente, em $\tau^{k}$ e $\tau^{l}$. No entanto, cabe o alerta de que a abordagem neoclássica implícita na formulação do modelo não leva em consideração o impacto sobre o bem-estar de alterações na distribuição funcional da renda, pois a renda da família representativa é igual à soma da renda do capital e do trabalho.

A análise empreendida neste texto tem outras limitações, apesar de estar próxima do estado da arte dessa literatura, pois o uso da solução do modelo como indicativo da evolução da economia tem implícita a hipótese de que o governo pode se comprometer com toda a trajetória dos instrumentos fiscais, que os consumidores têm pleno conhecimento deles, e que não há incerteza. Esse alerta é especialmente relevante na interpretação dos resultados das simulações de consolidação da dívida pública, quando o instrumento toma um valor na fase de estabilização e outro na fase posterior, pois pode ser difícil criar mecanismos pelos quais o governo se comprometeria com a segunda etapa da política.

Além disso, a aplicação rigorosa e inflexível das regras fiscais aqui simuladas pode resultar em um comportamento da dívida distinto do calculado, e potencialmente até explosivo, caso alguma das hipóteses do modelo seja violada. Pode não ser razoável manter a política fiscal inalterada caso se observe que ela esteja levando a um comportamento não estacionário da dívida pública. Uma alternativa natural, no espírito da teoria de controle de sistemas dinâmicos, seria adotar regras de ajuste das variáveis fiscais, em vez das metas rígidas para as suas trajetórias. O regime spend-and-tax, 
historicamente observado no Brasil (Issler e Lima 1998), pode ser visto como um tipo rudimentar de controle: quando há um aumento do gasto público e a dívida começa a superar o valor desejado, o governo age aumentando as alíquotas dos impostos. Entretanto, sabe-se que esta regra não é ótima, pois o governo não pode aumentar os impostos indefinidamente. Todavia, este modelo pode ser adaptado para ajudar no desenvolvimento de regras ótimas que possam reagir a diferenças entre a trajetória desejada e realizada, mas essa tarefa é deixada para pesquisas futuras.

\section{Referências}

Almeida, M.; Lisboa, M. B.; Pessôa, S. "O ajuste inevitável - o país que ficou velho antes de se tornar desenvolvido.” Folha de S.Paulo (Jun. 2015).

Almeida, V.; Divino, J. A.; Gadelha, S. R. D. B.; Maranhão, A. "Alíquotas tributárias efetivas médias para a economia brasileira: uma abordagem macroeconômica.” Revista Brasileira de Economia 71, no. 2., 2017.

AMBIMA - ASSOCIAÇÃO BRASILEIRA DAS ENTIDADES DOS MERCADOS FINANCEIROS E DE CAPITAIS. "Tributação de Ativos e Operações Financeiras - IR e IOF”, folheto, atualização de 12/01/2018. 2018. Aschauer, D. A. "Is public expenditure productive?” Journal of Monetary Economics 23: 177-200, 1989.

“Do States optimize? Public capital and economic growth.” Annals of Regional Science 34: 343-363, 2000.

Arestis, P. "Fiscal policy is still an effective instrument of macroeconomic policy." Panoeconomicus 2: 143156, 2011.

"Fiscal policy: a strong macroeconomic role." Review of Keynesian Economics 1: 93-108, 2012.

Azevedo, C.F.; Fasolo, A. M. "Effective tax rates on consumption and factor incomes: a quarterly frequency estimation for Brazil.” Brasília: BCB, 2015a. (Working Paper 398).

. "Alíquotas efetivas dos impostos sobre o consumo e a renda dos fatores: uma estimação em frequência trimestral para o Brasil.” Brasília: Tesouro Nacional, 2015b. (XX Prêmio Tesouro Nacional de Monografias).

Baier, S. L.; Glomm, G. "Long-run growth and welfare effects of public policies with distortionary taxation." Journal of Economic Dynamics and Control 12: 2007-2042, 2001.

BCB - BANCO CENTRAL DO BRASIL. "Sistema Gerenciador de Séries Temporais.” Brasília: BCB, 2018.

Ballard, C. L.; Fullerton, D.; Shoven, J. B.; Whalley, J. "A general equilibrium model for tax policy evaluation.” Chicago: University of Chicago Press, 1985.

Barbosa Filho, F.H.; Pessôa, S. A.; Veloso, F. A. "Evolução da Produtividade Total os Fatores na Economia Brasileira com Ênfase no Capital Humano - 1992-2007.” Revista Brasileira de Economia 64, no. 2: 91-113, 2010.

Barro, R. J. “Are Government bonds net wealth?” Journal of Political Economy 82, no. 6: 1095-1117, 1974.

. "Government spending in a simple model of endogenous growth." Journal of Political Economy 98, no. 5, part II: S103-S125, 1990.

Barro, R. J.; Sala-I-Martin, X. "Public finance in models of economic growth." Review of Economic Studies 59: 645-661, 1993.

“Economic Growth.” Cambridge, Massachusetts: MIT Press, 2004.

Estud. Econ., São Paulo, vol.50 n.1, p. 5-42, jan.-mar. 2020 
Baxter, M.; King, R. G. "Fiscal policy in general equilibrium.” The American Economic Review 83: 315-334, 1993. Bezerra, A. R. ; Pereira, R. A. ; Campos, F. D. A. O.; Callado, M. D. C. «Efeitos de crescimento e bem-estar da recomposição dos investimentos públicos no Brasil.” Pesquisa e Planejamento Econômico, ed. 44, n. 3, p. 579-607, 2014.

BRASIL. Secretaria de Política Econômica. "Relatório de análise econômica dos gastos públicos federais 20062015.” Brasília: Ministério da Fazenda, mai. 2016.

. Secretaria do Tesouro Nacional. "Relatório mensal da dívida pública": dezembro de 2016. Brasília: Ministério da Fazenda, mai. 2018.

Buchanan, J. M. "Barro on the Ricardian Equivalence Theorem." Journal of Political Economy 84, no. 2: 337-342, 1976.

Carvalho, F. C. “Equilíbrio fiscal e política econômica keynesiana.” Revista Análise Econômica 50: 7-25, 2008.

Caselli, F.; Esquivel, G.; Lefort, F. "Reopening the convergence debate: a new look at cross-country growth empirics.” Journal of Economic Growth 1, no. 3, p. 363-389, 1996.

Cass, D. "Optimum growth in an aggregative model of capital accumulation." The Review of Economic Studies no. 32: 233-240, 1965.

Christiano, L.J., Eichenbaum, M. "Current real business cycle theories and aggregate labor market fluctuations." The American Economic Review 82, no. 3: 430-450, 1992.

CODACE - COMITÊ DE DATAÇÃO DE CICLOS ECONÔOMICOS. Comunicado de 30/10/2017. Fundação Getulio Vargas (FGV), 2017. http://portalibre.fgv.br

Cooley, T. F.; Hansen, G. D. "Tax distortions in a neoclassical monetary economy." Journal of Economic Theory 58, no. 2: 290-316, 1992.

Davidson, P. “The neoclassical vs. post-keynesian view of government.” In: Davidson, P. Controversies in postkeynesian economics. Cheltenhan, UK: Edward Elgar Pub, 1991.

Devarajan, S.; Swaroop, V.; Zou, H. "The composition of public expenditure and economic growth." Journal of Monetary Economics 37: 313-344, 1996.

Dotsey, M.; Mao, C. S. "The Effects of Fiscal Policy in a Neoclassical Growth Model.” Baltimore: Federal Reserve Bank of Richmond, 1994. (Working Paper 94-03).

Ferreira, P. C.; Nascimento, L. G. "Welfare and growth effects of alternative fiscal rules for infrastructure investment in Brazil.” Rio de Janeiro: FGV, 2005. (Texto para Discussão).

Galí, J., López-Salido, J.D., Vallés, J. "Understanding the effects of government spending on consumption." Journal of European Economic Association 5, no. 1: 227-270, 2007.

GAMS DEVELOPMENT CORPORATION. “General Algebraic Modeling System (GAMS).” Versão: 24.2.1. Washington, DC, USA, 2013.

Giambiagi, F.; Além, A. C. "Finanças públicas: teoria e prática no Brasil." 5. ed. Rio de Janeiro: CampusElsevier, 2016.

Glomm, G.; Ravikumar, B. "Public investment in infrastructure in a simple growth model." Journal of Economic Dynamics and Control 18, no. 6: 1173-1187, 1994.

Gomes, F.A. R.; Paz, L. S. "Estimating the elasticity of intertemporal substitution: is the aggregate financial return free from the weak instrument problem?” Journal of Macroeconomics 36: 63-75, 2013.

Gomes, V.; Pessôa, S.A.; Veloso, F. A. "Evolução da produtividade total dos fatores na economia brasileira: uma análise comparativa.” Pesquisa e Planejamento Econômico 33, no.3: 389-434, 2003.

Gruber, J. "A Tax-based estimate of the elasticity of intertemporal substitution." Quarterly Journal of Finance 3 , no. 1, 2013.

FIPE - FUNDAÇÃO INSTITUTO DE PESQUISAS ECONÔMICAS. Investimento e poupança na economia brasileira 2000 - 2017: o crowding out do setor privado. Nota Centro de Estudos de Mercado de Capitais (CEMEC), n. 04/2018, mar. 2018. 
Hansen, L.P.; Sigleton, K.J. “Generalized Instrumental Variables Estimation of Nonlinear Rational Expectations Models." Econometrica 50, no. 5, p. 1269-128, 1982.

. "Stochastic Consumption, Risk Aversion, and the Temporal Behavior of Asset Returns." The Journal of Political Economy 91, no. 2: 249-265, 1983.

Hermann, J. “Ascensão e queda da política fiscal: de Keynes ao 'autismo fiscal' dos anos 1990-2000.” In: ENCONTRO DA ANPEC, 34., Salvador. Anais... Salvador: ANPEC, 2006.

IBGE - INSTITUTO BRASILEIRO DE GEOGRAFIA E ESTATÍSTICA. Sistema de Contas Nacionais - Tabelas Sinóticas 2010- 2016. Brasília: IBGE, 2018. Disponível em: < https://www.ibge.gov.br/estatisticas-novoportal/ economicas>.

IBRE - INSTITUTO BRASILEIRO DE ECONOMIA. O Brasil ainda é uma economia fechada, e isso não é bom para o desenvolvimento. Carta do IBRE, Fundação Getúlio Vargas (FGV), Rio de Janeiro, 2013.

IFI - INSTITUIÇÃO FISCAL INDEPENDENTE. Relatório de Acompanhamento Fiscal (RAF). Brasília: Senado Federal, fev. 2018.

Issler, J. V.; Lima, L. R. "Como se equilibra o orçamento do governo no Brasil: aumento de receitas ou corte de gastos?” Brasília: Tesouro Nacional, 1998. ( III Prêmio Tesouro Nacional de Monografias). Disponível em: < http://www3.tesouro.fazenda.gov.br/Premio_TN/iiipremio/financas/3lugar topicos_III_PTN/ISSLER_Joao_Victor.PDF>.

Issler, J. V.; Piqueira, N. S. "Estimating relative risk aversion, the discount rate, and the intertemporal elasticity of substitution in consumption for Brazil using three types of utility function." Brazilian Review of Econometrics 20, no2: 201-239, 2000.

Kydland, F.; Prescott, E. “Time to build and aggregate fluctuations.” Econometrica 50, no 6: 1345-1370, 1982.

Koopmans, T. C. “On the concept of optimal economic growth.” In: Johansen, J. (ed.). The econometric approach to development planning. Amsterdam: North Holland, 1965.

Kregel, J. A. "Budget deficits, stabilisation policy and liquidity preference: Keynes's post-war policy proposals." In: Vicarelli, F. (ed.). Keynes's relevance today. Londres: Palgrave Macmillan, 1985.

Lansing, K. J. "Optimal fiscal policy in a business cycle model with public capital." Canadian Journal of Economics 31: 337-364, 1998.

Leeper, E. M.; Yang, S. S. "Dynamic scoring: alternative financing schemes." Journal of Public Economics 92, no. 1: 159-182, 2008.

Leeper, E. M.; Walker, T. B.; Yang, C. S. "Government investment and fiscal stimulus." Journal of Monetary Economics 57, no. 8: 1000-1012, 2010.

Liu, F. ; Sercu, P. "Estimating the intertemporal substitution elasticity." SSRN Eletronic Journal, Feb. 2009.

Lluch, C.; Powel, A. A.; Williams, R. A. Patterns in household demand and saving. Washington, USA: Oxford University Press, World Bank, 1977.

Lopes, M. L. M.; Mollo, M. L. R. "O debate sobre a redução do deficit fiscal no Brasil: uma crítica pós-keynesiana.” Nova Economia 21, no p. 67-103, 2011.

Lucas, R. E. "Supply-side economics: an analytical review." Oxford Economic Papers 42: 293-316, 1990.

Ludvigson, S. "The macroeconomic effects of government debt in a stochastic growth model." Journal of Monetary Economics 38, no. 1: 25-45, 1996.

Mereb, J.; Zilberman, E. “O Programa de Aceleração do Crescimento acelera o crescimento?” Rio de Janeiro: Departamento de Economia da PUC/RIO, 2013. (Texto para Discussão, n. 613).

Montes, G. C.; Alves, R. C. “Teoria das finanças funcionais e o papel da política fiscal: uma crítica pós-keynesiana ao novo consenso macroeconômico." Revista de Economia Politica 32, no. 4: 670-688, 2012a.

. "O debate acerca dos objetivos e condução da política fiscal: uma abordagem crítica à visão convencional." Economia e Sociedade 21, no. 2: 363-386, 2012 b.

Mussolini, C. C.; Teles, V. K. “Ciclos reais e política fiscal no Brasil.” Estudos Econômicos 42, no. 1: 75-96, 2012. 
Oreiro, J. L.; Sicsú, J.; Paula, L. F. “Controle da Dívida Pública e Política Fiscal: uma Alternativa para um Crescimento Auto-sustentado da Economia Brasileira.” In: Sicsú, J.; Oreiro, J. L.; Paula, L. F. de. (Org.). Agenda Brasil: políticas econômicas para o crescimento com estabilidade de preços. Barueri: Manole, 2003.

Orair, R. O. "O investimento público no Brasil: trajetória e relações com o regime fiscal.” Brasília: Ipea, 2016. (Texto para Discussão, n. 2215).

Paes, N. L.; Bugarin, M. N. S. "Reforma Tributária: impactos distributivos, sobre o bem-estar e a progressividade." Revista Brasileira de Economia 60, no. 1: 33-56, 2006.

Papageorgiou, D. "Fiscal policy reforms in general equilibrium: the case of Greece." Journal of Macroeconomics 34, no. 2: 504-522, 2012.

Pereira, R. A.; Ferreira, P. C. "Avaliação dos impactos macroeconômicos e de bem-estar da reforma tributária no Brasil." Revista Brasileira de Economia 64, no. 2: 191-208, 2010.

Ramsey, F. “A Mathematical Theory of Saving.” Economic Journal 38: 543-559, 1928.

Rebelo, S. T. "Long run policy analysis and long run growth." The Journal of Political Economy 99, no. 3: 500-521, 1991.

Reinhart, C.M.; Rogoff, K.S. “Growth in a time of debt." American Economic Review 100, no. 2: 573-578, 2010. . "From Financial Crash to Debt Crisis." American Economic Review 101: 1676-1706, 2011.

Rocha, F. "Política fiscal através do ciclo e operação dos estabilizadores fiscais." EconomiA 10, no. 3: 483-499, 2009.

Saint-Paul, G. "Fiscal Policy in an Endogenous Growth Model." The Quarterly Journal of Economics 107, no. 4: 1243-1259, 1992.

Santana, P.; Cavalcanti, T. V. De V.; Paes, N. L. "Impactos de longo prazo de reformas fiscais sobre a economia brasileira." Revista Brasileira de Economia 66, no. 2: 247-269, 2012.

Teles, V. K.; Mussolini, C. C. "Public debt and the limits of fiscal policy to increase economic growth." European Economic Review no. 66: 1-15, 2014.

Tourinho, O. A. F.; Mercês, G. M. R.; Costa, J. G. "Public debt in Brazil: sustentability and its implication." EconomiA 14: 233-250, 2013.

Tourinho, O. A. F.; Sangoi, R. "Dívida pública e crescimento econômico: testes da hipótese de Reinhart e Rogoff." Economia Aplicada 21, no. 3: 437-464, 2017.

Turnovsky, S. J. "Optimal tax, debt and expenditures policies in a growing economy." Journal of Public Economics 60: 21-44, 1996.

. "Fiscal policy in a growing economy with public capital." Macroeconomic Dynamics 1: 615-635, 1997.

"On the role of government in a stochastically growing open economy." Journal of Economic Dynamics and Control 23: 973-908. 1999.

Uhlig, H. "Some fiscal calculus." The American Economic Review 100, no. 2: 30-34, 2010.

Varian, H. "Microeonomic Analysis." 3rd. ed. New York: Norton, 1992.

Yogo, M. "Estimating the elasticity of intertemporal substitution when instruments are weak." The Review of Economics and Statistics 86, no. 3: 797-810, 2004.

WORLD BANK. WDI - World Development Indicators. Washington: World Bank, 2018. Disponível em: <http:// databank.worldbank.org/>.

Zagler, M.; Dürnecker, G. "Fiscal policy and economic growth.” Journal of Economic Surveys 17, no. 3: 397418, 2003. 